\title{
Are Prescription Stimulants "Smart Pills"? The Epidemiology and Cognitive Neuroscience of Prescription Stimulant Use by Normal Healthy Individuals
}

\author{
M. Elizabeth Smith and Martha J. Farah \\ University of Pennsylvania
}

\begin{abstract}
Use of prescription stimulants by normal healthy individuals to enhance cognition is said to be on the rise. Who is using these medications for cognitive enhancement, and how prevalent is this practice? Do prescription stimulants in fact enhance cognition for normal healthy people? We review the epidemiological and cognitive neuroscience literatures in search of answers to these questions. Epidemiological issues addressed include the prevalence of nonmedical stimulant use, user demographics, methods by which users obtain prescription stimulants, and motivations for use. Cognitive neuroscience issues addressed include the effects of prescription stimulants on learning and executive function, as well as the task and individual variables associated with these effects. Little is known about the prevalence of prescription stimulant use for cognitive enhancement outside of student populations. Among college students, estimates of use vary widely but, taken together, suggest that the practice is commonplace. The cognitive effects of stimulants on normal healthy people cannot yet be characterized definitively, despite the volume of research that has been carried out on these issues. Published evidence suggests that declarative memory can be improved by stimulants, with some evidence consistent with enhanced consolidation of memories. Effects on the executive functions of working memory and cognitive control are less reliable but have been found for at least some individuals on some tasks. In closing, we enumerate the many outstanding questions that remain to be addressed by future research and also identify obstacles facing this research.
\end{abstract}

Keywords: amphetamine, enhancement, neuroethics, psychopharmacology, stimulant

A "smart pill" is a drug that increases the cognitive ability of anyone taking it, whether the user is cognitively impaired or normal. The Romanian neuroscientist Corneliu Giurgea is often credited with first proposing, in the 1960s, that smart pills should be developed to increase the intelligence of the general population (see Giurgea, 1984). He is quoted as saying, "Man is not going to wait passively for millions of years before evolution offers him a better brain" (Gazzaniga, 2005, p. 71). In their best-selling book, Smart Drugs and Nutrients, Dean and Morgenthaler (1990) reviewed a large number of substances that have been used by healthy individuals with the goal of increasing cognitive ability. These include synthetic and natural products that affect neurotransmitter levels, neurogenesis, and blood flow to the brain. Although many of these substances have their adherents, none

M. Elizabeth Smith, Department of Psychology, University of Pennsylvania; Martha J. Farah, Center for Cognitive Neuroscience, University of Pennsylvania.

The writing of this article was supported by Office of Naval Research Grant N000140710034 and National Institutes of Health Grant R01HD055689. We thank Larry Diller, Nicolas Rasmussen, and Steven Hinshaw for insightful comments on an earlier version of this article.

Correspondence concerning this article should be addressed to Martha J. Farah, Center for Cognitive Neuroscience, University of Pennsylvania, 3720 Walnut Street, Philadelphia, PA 19104. E-mail: mfarah@psych .upenn.edu have become widely used. Caffeine and nicotine may be exceptions to this generalization, as one motivation among many for their use is cognitive enhancement (Julien, 2001).

Another class of substances with the potential to enhance cognition in normal healthy individuals is the class of prescription stimulants used to treat attention-deficit/hyperactivity disorder (ADHD). These include methylphenidate (MPH), best known as Ritalin or Concerta, and amphetamine (AMP), most widely prescribed as mixed AMP salts consisting primarily of dextroamphetamine (d-AMP), known by the trade name Adderall. These medications have become familiar to the general public because of the growing rates of diagnosis of ADHD children and adults (Froehlich et al., 2007; Sankaranarayanan, Puumala, \& Kratochvil, 2006) and the recognition that these medications are effective for treating ADHD (MTA Cooperative Group, 1999; Swanson et al., 2008).

To judge from recent reports in the popular media, healthy people have also begun to use MPH and AMPs for cognitive enhancement. Major daily newspapers such as The New York Times, The LA Times, and The Wall Street Journal; magazines including Time, The Economist, The New Yorker, and Vogue; and broadcast news organizations including the BBC, CNN, and NPR have reported a trend toward growing use of prescription stimulants by healthy people for the purpose of enhancing school or work performance.

Nature magazine conducted a poll asking its readers about their cognitive-enhancement practices and their attitudes toward cogni- 
tive enhancement. Hundreds of college faculty and other professionals responded, and approximately one fifth reported using drugs for cognitive enhancement, with Ritalin being the most frequently named (Maher, 2008). However, the nature of the sample-readers choosing to answer a poll on cognitive enhancement-is not representative of the academic or general population, making the results of the poll difficult to interpret. By analogy, a poll on Vermont vacations, asking whether people vacation in Vermont, what they think about Vermont, and what they do if and when they visit, would undoubtedly not yield an accurate estimate of the fraction of the population that takes its vacations in Vermont.

The ethics of cognitive enhancement have been extensively debated in the academic literature (e.g., Bostrom \& Sandberg, 2009; Farah et al., 2004; Greely et al., 2008; Mehlman, 2004; Sahakian \& Morein-Zamir, 2007). We do not attempt to review this aspect of the problem here. Rather, we attempt to provide a firmer empirical basis for these discussions. Despite the widespread interest in the topic and its growing public health implications, there remains much researchers do not know about the use of prescription stimulants for cognitive enhancement.

Among the questions to be addressed in the present article are, How widespread is the use of prescription stimulants for cognitive enhancement? Who uses them, for what specific purposes? Given that nonmedical use of these substances is illegal, how are they obtained? Furthermore, do these substances actually enhance cognition? If so, what aspects of cognition do they enhance? Is everyone able to be enhanced, or are some groups of healthy individuals helped by these drugs and others not? The goal of this article is to address these questions by reviewing and synthesizing findings from the existing scientific literature. We begin with a brief overview of the psychopharmacology of the two most commonly used prescription stimulants.

\section{History and Psychopharmacology of Amphetamine and Methylphenidate}

AMP was first investigated as an asthma medication in the 1920s, but its psychological effects were soon noticed. These included increased feelings of energy, positive mood, and prolonged physical endurance and mental concentration. These effects have been exploited in a variety of medical and nonmedical applications in the years since they were discovered, including to treat depression, to enhance alertness in military personnel, and to provide a competitive edge in athletic competition (Rasmussen, 2008). Today, AMP remains a widely used and effective treatment for ADHD (Wilens, 2006).

MPH was developed more recently and marketed primarily for ADHD, although it is sometimes prescribed off label or used nonmedically to increase alertness, energy, or concentration in conditions other than ADHD. Both MPH and AMP are on the list of substances banned from sports competitions by the World Anti-Doping Agency (Docherty, 2008). Both also have the potential for abuse and dependence, which detracts from their usefulness and is the reason for their classification as Schedule II controlled substances. Although the risk of developing dependence on these drugs is believed to be low for individuals taking them for ADHD, the Schedule II classification indicates that these drugs have a high potential for abuse and that abuse may lead to severe dependence.
The beneficial effects as well as the potentially serious side effects of these drugs can be understood in terms of their effects on the catecholamine neurotransmitters dopamine and norepinephrine (Wilens, 2006). These neurotransmitters play an important role in cognition, affecting the cortical and subcortical systems that enable people to focus and flexibly deploy attention (Robbins \& Arnsten, 2009). In addition, the brain's reward centers are innervated by dopamine neurons, accounting for the pleasurable feelings engendered by these stimulants (Robbins \& Everett, 1996).

The therapeutic effect of AMP and MPH in ADHD is consistent with the finding of abnormalities in the catecholamine system in individuals with ADHD (e.g., Volkow et al., 2007). Both AMP and MPH exert their effects on cognition primarily by increasing levels of catecholamines in prefrontal cortex and the cortical and subcortical regions projecting to it, and this mechanism is responsible for improving cognition and behavior in ADHD (Pliszka, 2005; Wilens, 2006).

AMP and MPH increase catecholamine activity in different ways. MPH primarily inhibits the reuptake of dopamine by presynaptic neurons, thus leaving more dopamine in the synapse and available for interacting with the receptors of the postsynaptic neuron. AMP also affects reuptake, as well as increasing the rate at which neurotransmitter is released from presynaptic neurons (Wilens, 2006). These effects are manifest in the attention systems of the brain, as already mentioned, and in a variety of other systems that depend on catecholaminergic transmission as well, giving rise to other physical and psychological effects. Physical effects include activation of the sympathetic nervous system (i.e., a fight-or-flight response), producing increased heart rate and blood pressure. Psychological effects are mediated by activation of the nucleus accumbens, ventral striatum, and other parts of the brain's reward system, producing feelings of pleasure and the potential for dependence.

\section{Are Prescription Stimulants Being Used as Smart Pills?}

\section{Large U.S. Government Surveys}

Most epidemiological research on nonmedical stimulant use has been focused on issues relevant to traditional problems of drug abuse and addiction, and so, stimulant use for cognitive enhancement is not generally distinguished from use for other purposes, such as staying awake or getting high. As Boyd and McCabe (2008) pointed out, the large national surveys of nonmedical prescription drug use have so far failed to distinguish the ways and reasons that people use the drugs, and this is certainly true where prescription stimulants are concerned. The largest survey to investigate prescription stimulant use in a nationally representative sample of Americans, the National Survey on Drug Use and Health (NSDUH), phrases the question about nonmedical use as follows: "Have you ever, even once, used any of these stimulants when they were not prescribed for you or that you took only for the experience or feeling they caused?" (Snodgrass \& LeBaron 2007). This phrasing does not strictly exclude use for cognitive enhancement, but it emphasizes the noncognitive effects of the drugs. In 2008, the NSDUH found a prevalence of $8.5 \%$ for lifetime nonmedical stimulant use by Americans over the age of 12 years and a 
prevalence of $12.3 \%$ for Americans between 21 and 25 (Substance Abuse and Mental Health Services Administration, 2009).

In addition, large national surveys, including the NSDUH, have generally classified prescription stimulants with other stimulants including street drugs such as methamphetamine. For example, since 1975, the National Institute on Drug Abuse-sponsored Monitoring the Future (MTF) survey has gathered data on drug use by young people in the United States (Johnston, O’Malley, Bachman, \& Schulenberg, 2009a, 2009b). Originally, MTF grouped prescription stimulants under a broader class of stimulants so that respondents were asked specifically about MPH only after they had indicated use of some drug in the category of AMPs. As rates of MPH prescriptions increased and anecdotal reports of nonmedical use grew, the 2001 version of the survey was changed to include a separate standalone question about MPH use. This resulted in more than a doubling of estimated annual use among 12th graders, from $2.4 \%$ to $5.1 \%$. More recent data from the MTF suggests Ritalin use has declined (3.4\% in 2008). However, this may still underestimate use of $\mathrm{MPH}$, as the question refers specifically to Ritalin and does not include other brand names such as Concerta (an extended release formulation of MPH).

Turning to analyses related specifically to the drugs that are the subject of this article, reanalysis of the 2002 NSDUH data by Kroutil and colleagues (2006) found past-year nonmedical use of stimulants other than methamphetamine by $2 \%$ of individuals between the ages of 18 and 25 and by $0.3 \%$ of individuals 26 years of age and older. For ADHD medications in particular, these rates were $1.3 \%$ and $0.1 \%$, respectively. Finally, Novak, Kroutil, Williams, and Van Brunt (2007) surveyed a sample of over four thousand individuals from the Harris Poll Online Panel and found that $4.3 \%$ of those surveyed between the ages of 18 and 25 had used prescription stimulants nonmedically in the past year, compared with only $1.3 \%$ between the ages of 26 and 49 .

\section{Surveys of Student Nonmedical Stimulant Use}

We reviewed recent studies concerning prescription stimulant use specifically among students in the United States and Canada, using the method illustrated in Figure 1. Although less informative about the general population, these studies included questions about students' specific reasons for using the drugs, as well as frequency of use and means of obtaining them. These studies typically found rates of use greater than those reported by the nationwide NSDUH or the MTF surveys. This probably reflects a true difference in rates of usage among the different populations.
In support of that conclusion, the NSDUH data for college age Americans showed that college students were considerably more likely than nonstudents of the same age to use prescription stimulants nonmedically (odds ratio: 2.76; Herman-Stahl, Krebs, Kroutil, \& Heller, 2007).

Table 1 shows all of the studies of middle school, secondary T1,AQ:1 school, and college students that we identified. As indicated in the table, the studies are heterogeneous, with varying populations sampled, sample sizes, and year of data collection, and they focused on different subsets of the epidemiological questions addressed here, including prevalence and frequency of use, motivations for use, and method of obtaining the medication.

Prevalence and frequency of use. Four of the studies focused on middle and high school students, with varied results. Boyd, McCabe, Cranford, and Young (2006) found a 2.3\% lifetime prevalence of nonmedical stimulant use in their sample, and McCabe, Teter, and Boyd (2004) found a $4.1 \%$ lifetime prevalence in public school students from a single American public school district. Poulin (2001) found an 8.5\% past-year prevalence in public school students from four provinces in the Atlantic region of Canada. A more recent study of the same provinces found a $6.6 \%$ and $8.7 \%$ past-year prevalence for MPH and AMP use, respectively (Poulin, 2007).

By the end of 2009, at least 25 studies reported surveys of college students' rates of nonmedical stimulant use. Of the studies using relatively smaller samples, prevalence was, in chronological order, $16.6 \%$ (lifetime; Babcock \& Byrne, 2000), 35.3\% (past year; Low \& Gendaszek, 2002), 13.7\% (lifetime; Hall, Irwin, Bowman, Frankenberger, \& Jewett, 2005), 9.2\% (lifetime; Carroll, McLaughlin, \& Blake, 2006), and 55\% (lifetime, fraternity students only; DeSantis, Noar, \& Web, 2009). Of the studies using samples of more than a thousand students, somewhat lower rates of nonmedical stimulant use were found, although the range extends into the same high rates as the small studies: $2.5 \%$ (past year, Ritalin only; Teter, McCabe, Boyd, \& Guthrie, 2003), 5.4\% (past year; McCabe \& Boyd, 2005), 4.1\% (past year; McCabe, Knight, Teter, \& Wechsler, 2005), 11.2\% (past year; Shillington, Reed, Lange, Clapp, \& Henry, 2006), 5.9\% (past year; Teter, McCabe, LaGrange, Cranford, \& Boyd, 2006), 16.2\% (lifetime; White, BeckerBlease, \& Grace-Bishop, 2006), 1.7\% (past month; Kaloyanides, McCabe, Cranford, \& Teter, 2007), 10.8\% (past year; Arria, O’Grady, Caldeira, Vincent, \& Wish, 2008); 5.3\% (MPH only, lifetime; DuPont, Coleman, Bucher, \& Wilford, 2008); 34\% (lifetime; DeSantis,

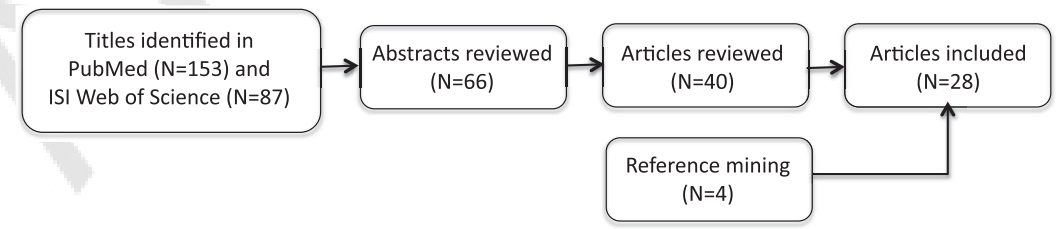

Figure 1. Flow diagram of epidemiology literature search completed July 1, 2010. Search terms were nonmedical use, nonmedical use, misuse, or illicit use, and prescription stimulants, dextroamphetamine, methylphenidate, Ritalin, or Adderall. Stages of subsequent review used the information contained in the titles, abstracts, and articles to determine whether articles reported studies of the extent of nonmedical prescription stimulant use by students and related questions addressed in the present article including students' motives and frequency of use. 


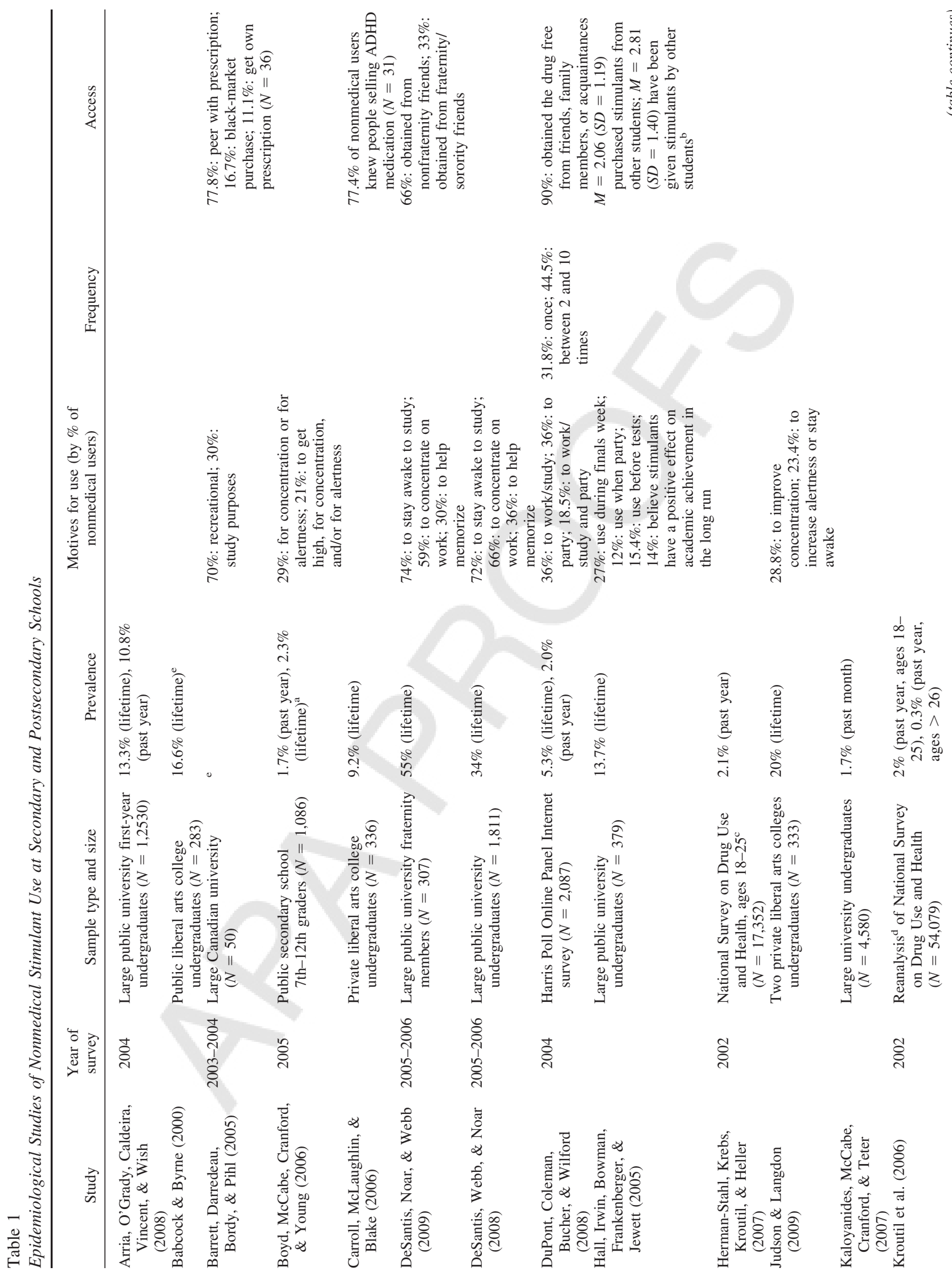




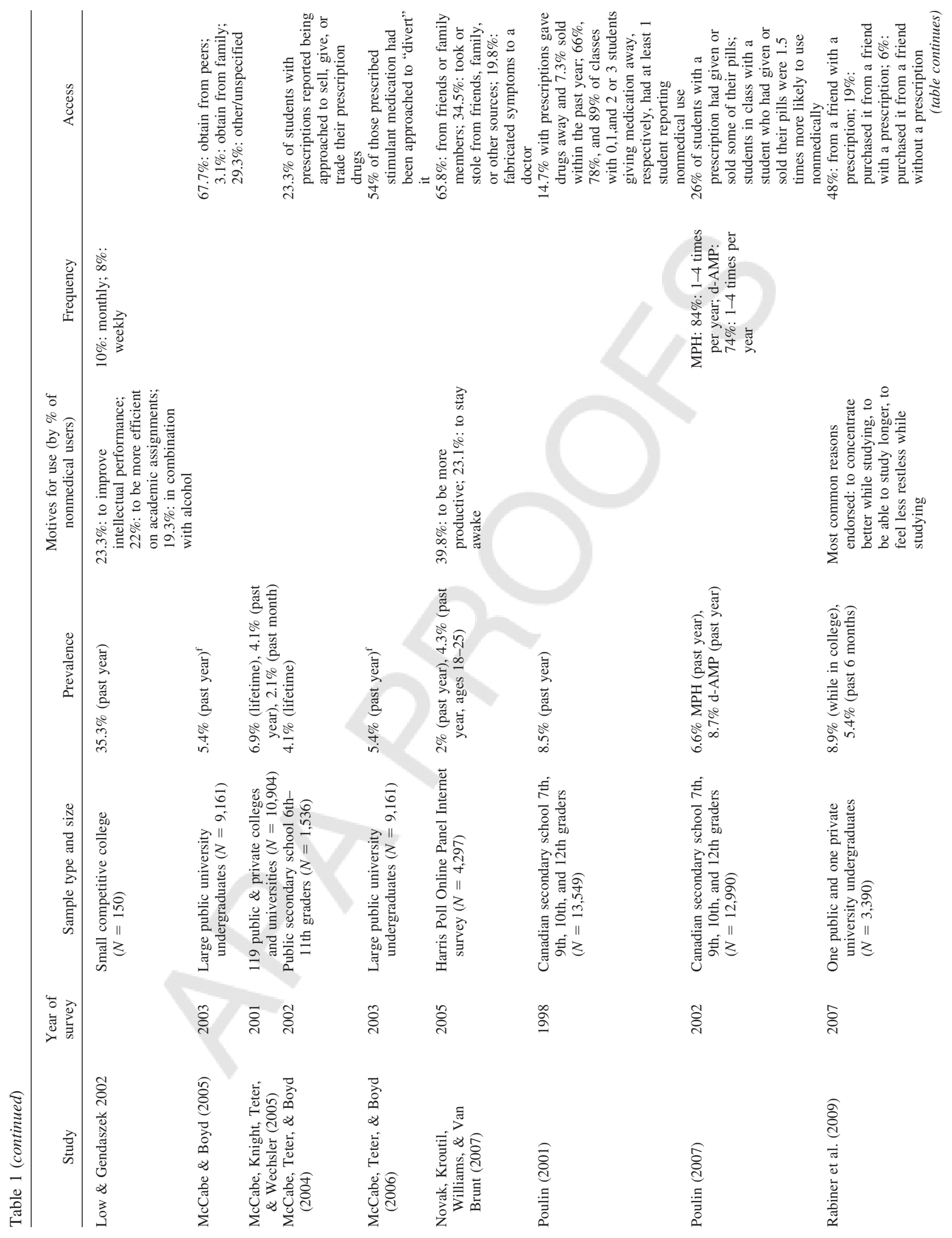


SMITH AND FARAH

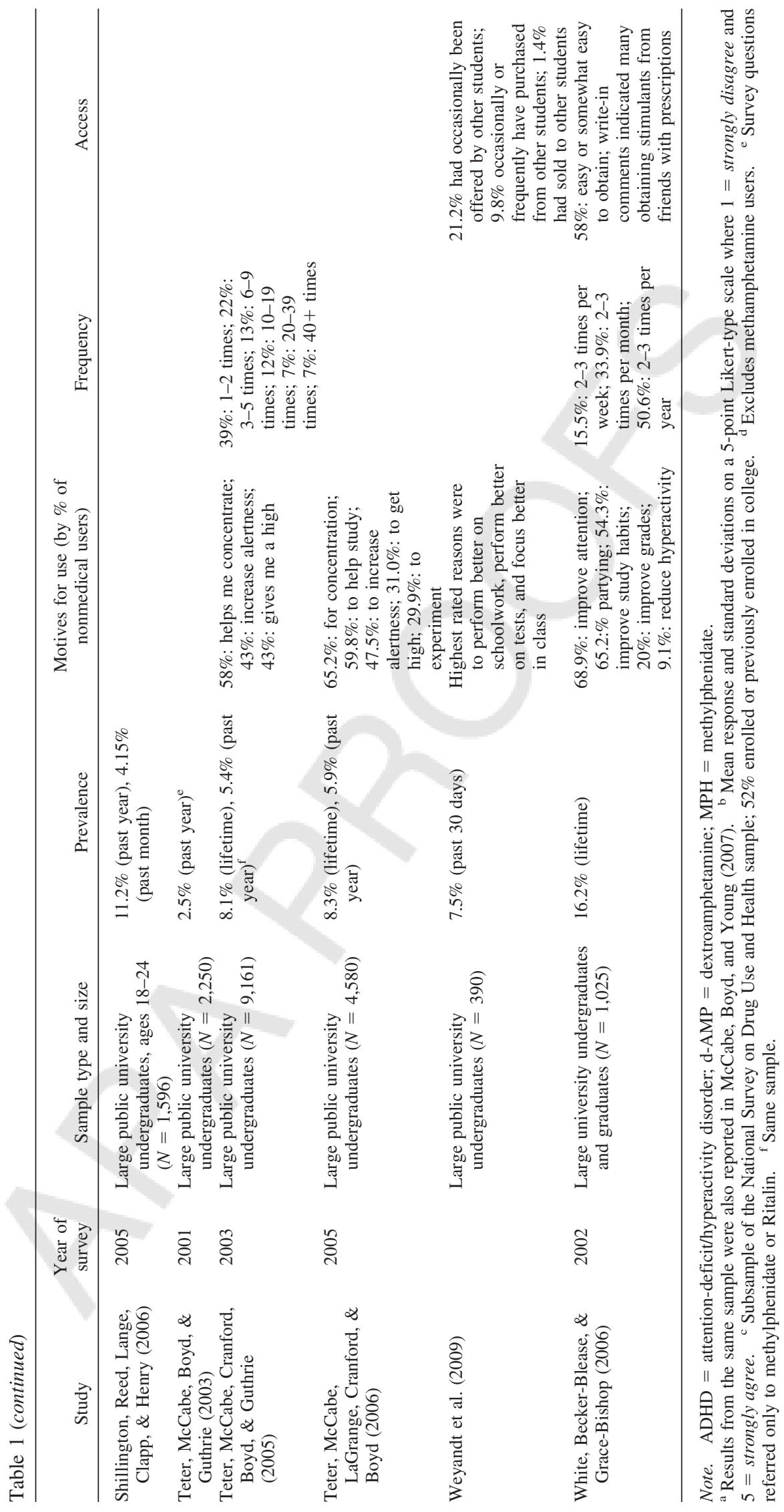


Webb, \& Noar, 2008), 8.9\% (lifetime; Rabiner et al., 2009), and 7.5\% (past month; Weyandt et al., 2009).

The question of how much nonmedical use of stimulants occurs on college campuses is only partly answered by the proportion of students using the drugs in this way. The other part of the answer is how frequently they are used by those students. Three studies addressed this issue. Low and Gendaszek (2002) found a high past-year rate of $35.3 \%$, but only $10 \%$ and $8 \%$ of this population used monthly and weekly, respectively. White et al. (2006) found a larger percentage used frequently: $15.5 \%$ using two to three times per week and $33.9 \%$ using two to three times per month. Teter et al. (2006) found that most nonmedical users take prescription stimulants sporadically, with well over half using five or fewer times and nearly $40 \%$ using only once or twice in their lives. DeSantis et al. (2008) offered qualitative evidence on the issue, reporting that students often turned to stimulants at exam time only, particularly when under pressure to study for multiple exams at the same time. Thus, there appears to be wide variation in the regularity of stimulant use, with the most common pattern appearing to be infrequent use.

Overall, the studies listed in Table 1 vary in ways that make it difficult to draw precise quantitative conclusions from them, including their definitions of nonmedical use, methods of sampling, and demographic characteristics of the samples. For example, some studies defined nonmedical use in a way that excluded anyone for whom a drug was prescribed, regardless of how and why they used it (Carroll et al., 2006; DeSantis et al., 2008, 2009; Kaloyanides et al., 2007; Low \& Gendaszek, 2002; McCabe \& Boyd, 2005; McCabe et al., 2004; Rabiner et al., 2009; Shillington et al., 2006; Teter et al., 2003, 2006; Weyandt et al., 2009), whereas others focused on the intent of the user and counted any use for nonmedical purposes as nonmedical use, even if the user had a prescription (Arria et al., 2008; Babcock \& Byrne, 2000; Boyd et al., 2006; Hall et al., 2005; Herman-Stahl et al., 2007; Poulin, 2001, 2007; White et al., 2006), and one did not specify its definition (Barrett, Darredeau, Bordy, \& Pihl, 2005). Some studies sampled multiple institutions (DuPont et al., 2008; McCabe \& Boyd, 2005; Poulin, 2001, 2007), some sampled only one (Babcock \& Byrne, 2000; Barrett et al., 2005; Boyd et al., 2006; Carroll et al., 2006; Hall et al., 2005; Kaloyanides et al., 2007; McCabe \& Boyd, 2005; McCabe et al., 2004; Shillington et al., 2006; Teter et al., 2003, 2006; White et al., 2006), and some drew their subjects primarily from classes in a single department at a single institution (DeSantis et al., 2008, 2009; Low \& Gendaszek, 2002). With few exceptions, the samples were all drawn from restricted geographical areas. Some had relatively high rates of response (e.g., 93.8\%; Low \& Gendaszek 2002) and some had low rates (e.g., 10\%; Judson \& Langdon, 2009), the latter raising questions about sample representativeness for even the specific population of students from a given region or institution.

In the largest nationwide study, McCabe et al. (2005) sampled 10,904 students at 119 public and private colleges and universities across the United States, providing the best estimate of prevalence among American college students in 2001, when the data were collected. This survey found $6.9 \%$ lifetime, $4.1 \%$ past-year, and $2.1 \%$ past-month nonmedical use of a prescription stimulant. It also found that prevalence depended strongly on student and school characteristics, consistent with the variability noted among the results of single-school studies. The strongest predictors of past-year nonmedical stimulant use by college students were admissions criteria (competitive and most competitive more likely than less competitive), fraternity/sorority membership (members more likely than nonmembers), and gender (males more likely than females).

Access. As already mentioned, AMPs and MPH are classified by the U.S. Food and Drug Administration (FDA) as Schedule II substances, which means that buying or selling them is a felony offense. This raises the question of how the drugs are obtained by students for nonmedical use. Several studies addressed this question and yielded reasonably consistent answers.

The majority of nonmedical users reported obtaining prescription stimulants from a peer with a prescription (Barrett et al., 2005; Carroll et al., 2006; DeSantis et al., 2008, 2009; DuPont et al., 2008; McCabe \& Boyd, 2005; Novak et al., 2007; Rabiner et al., 2009; White et al., 2006). Consistent with nonmedical user reports, McCabe, Teter, and Boyd (2006) found 54\% of prescribed college students had been approached to divert (sell, exchange, or give) their medication. Studies of secondary school students supported a similar conclusion (McCabe et al., 2004; Poulin, 2001, 2007). In Poulin's (2007) sample, $26 \%$ of students with prescribed stimulants reported giving or selling some of their medication to other students in the past month. She also found that the number of students in a class with medically prescribed stimulants was predictive of the prevalence of nonmedical stimulant use in the class (Poulin, 2001). In McCabe et al.'s (2004) middle and high school sample, $23 \%$ of students with prescriptions reported being asked to sell or trade or give away their pills over their lifetime.

Student motivations for nonmedical use of prescription stimulants. How much of the nonmedical use of prescription stimulants documented by these studies was for cognitive enhancement? Prescription stimulants could be used for purposes other than cognitive enhancement, including for feelings of euphoria or energy, to stay awake, or to curb appetite. Were they being used by students as smart pills or as "fun pills," "awake pills," or "diet pills"? Of course, some of these categories are not entirely distinct. For example, by increasing the wakefulness of a sleep-deprived person or by lifting the mood or boosting the motivation of an apathetic person, stimulants are likely to have the secondary effect of improving cognitive performance. Whether and when such effects should be classified as cognitive enhancement is a question to which different answers are possible, and none of the studies reviewed here presupposed an answer. Instead, they show how the respondents themselves classified their reasons for nonmedical stimulant use.

A total of 14 studies surveyed reasons for using prescription stimulants nonmedically, all but one study confined to student respondents. The most common reasons were related to cognitive enhancement. Different studies worded the multiple-choice alternatives differently, but all of the following appeared among the top reasons for using the drugs: "concentration" or "attention" (Boyd et al., 2006; DeSantis et al., 2008, 2009; Rabiner et al., 2009; Teter et al., 2003, 2006; Teter, McCabe, Cranford, Boyd, \& Guthrie, 2005; White et al., 2006); "help memorize," "study," "study habits," or "academic assignments" (Arria et al., 2008; Barrett et al., 2005; Boyd et al., 2006; DeSantis et al., 2008, 2009; DuPont et al., 2008; Low \& Gendaszek, 2002; Rabiner et al., 2009; Teter et al., 2005, 2006; White et al., 2006); "grades" or "intellectual performance" (Low \& Gendaszek, 2002; White et al., 2006); "before 
tests" or "finals week" (Hall et al., 2005); "alertness" (Boyd et al., 2006; Hall et al., 2005; Teter et al., 2003, 2005, 2006); or “performance" (Novak et al., 2007). However, every survey found other motives mentioned as well. The pills were also taken to "stay awake," "get high," "be able to drink and party longer without feeling drunk," "lose weight," "experiment," and for "recreational purposes."

\section{Do Prescription Stimulants Work as Smart Pills?}

The surveys just reviewed indicate that many healthy, normal students use prescription stimulants to enhance their cognitive performance, based in part on the belief that stimulants enhance cognitive abilities such as attention and memorization. Of course, it is possible that these users are mistaken. One possibility is that the perceived cognitive benefits are placebo effects. Another is that the drugs alter students' perceptions of the amount or quality of work accomplished, rather than affecting the work itself (Hurst, Weidner, \& Radlow, 1967). A third possibility is that stimulants enhance energy, wakefulness, or motivation, which improves the quality and quantity of work that students can produce with a given, unchanged, level of cognitive ability. To determine whether these drugs enhance cognition in normal individuals, their effects on cognitive task performance must be assessed in relation to placebo in a masked study design.

A number of different laboratory studies have assessed the acute effect of prescription stimulants on the cognition of normal adults. In the next four sections, we review this literature, with the goal of answering the following questions: First, do MPH (e.g., Ritalin) and d-AMP (by itself or as the main ingredient in Adderall) improve cognitive performance relative to placebo in normal healthy adults? Second, which cognitive systems are affected by these drugs? Third, how do the effects of the drugs depend on the individual using them?

Accordingly, we searched the literature for studies in which MPH or d-AMP was administered orally to nonelderly adults in a placebo-controlled design. Some of the studies compared the effects of multiple drugs, in which case we report only the results of stimulant-placebo comparisons; some of the studies compared the effects of stimulants on a patient group and on normal control subjects, in which case we report only the results for control subjects. The studies varied in many other ways, including the types of tasks used, the specific drug used, the way in which dosage was determined (fixed dose or weight-dependent dose), sample size, and subject characteristics (e.g., age, college sample or not, gender). Our approach to the classic splitting versus lumping dilemma has been to take a moderate lumping approach. We group studies according to the general type of cognitive process studied and, within that grouping, the type of task. The drug and dose are reported, as well as sample characteristics, but in the absence of pronounced effects of these factors, we do not attempt to make generalizations about them.

We included studies of the effects of these drugs on cognitive processes including learning, memory, and a variety of executive functions, including working memory and cognitive control. These studies are listed in Table 2, along with each study's sample size, gender, age and tasks administered. Given our focus on cognition enhancement, we excluded studies whose measures were confined to perceptual or motor abilities. Studies of attention are included when the term attention refers to an executive function but not when it refers to the kind of perceptual process taxed by, for example, visual search or dichotic listening or when it refers to a simple vigilance task. Vigilance may affect cognitive performance, especially under conditions of fatigue or boredom, but a more vigilant person is not generally thought of as a smarter person, and therefore, vigilance is outside of the focus of the present review. The search and selection process is summarized in Figure 2.

For the sake of organizing the review, we have divided the literature according to the general type of cognitive process being studied, with sections devoted to learning and to various kinds of executive function. Executive function is a broad and, some might say, vague concept that encompasses the processes by which individual perceptual, motoric, and mnemonic abilities are coordinated to enable appropriate, flexible task performance, especially in the face of distracting stimuli or alternative competing responses. Two major aspects of executive function are working memory and cognitive control, responsible for the maintenance of information in a short-term active state for guiding task performance and responsible for inhibition of irrelevant information or responses, respectively. A large enough literature exists on the effects of stimulants on these two executive abilities that separate sections are devoted to each. In addition, a final section includes studies of miscellaneous executive abilities including planning, fluency, and reasoning that have also been the subjects of published studies.

Because executive functions tend to work in concert with one another, these three categories are somewhat overlapping. For example, tasks that require working memory also require a degree of cognitive control to prevent current stimuli from interfering with the contents of working memory, and tasks that require planning, fluency, and reasoning require working memory to hold the task goals in mind. The assignment of studies to sections was based on best fit, according to the aspects of executive function most heavily taxed by the task, rather than exclusive category membership. Within each section, studies are further grouped according to the type of task and specific type of learning, working memory, cognitive control, or other executive function being assessed.

The question of whether stimulants are smart pills in a pragmatic sense cannot be answered solely by consideration of the statistical significance of the difference between stimulant and placebo. A drug with tiny effects, even if statistically significant, would not be a useful cognitive enhancer for most purposes. We therefore report Cohen's $d$ effect size measure for published studies that provide either means and standard deviations or relevant $F$ or $t$ statistics (Thalheimer \& Cook, 2002). More generally, with most sample sizes in the range of a dozen to a few dozen, small effects would not reliably be found.

\section{Do Prescription Stimulants Enhance Learning?}

Most people would describe school as a place where they go to learn, so learning is an especially relevant cognitive process for students to enhance. Even outside of school, however, learning plays a role in most activities, and the ability to enhance the retention of information would be of value in many different occupational and recreational contexts. 


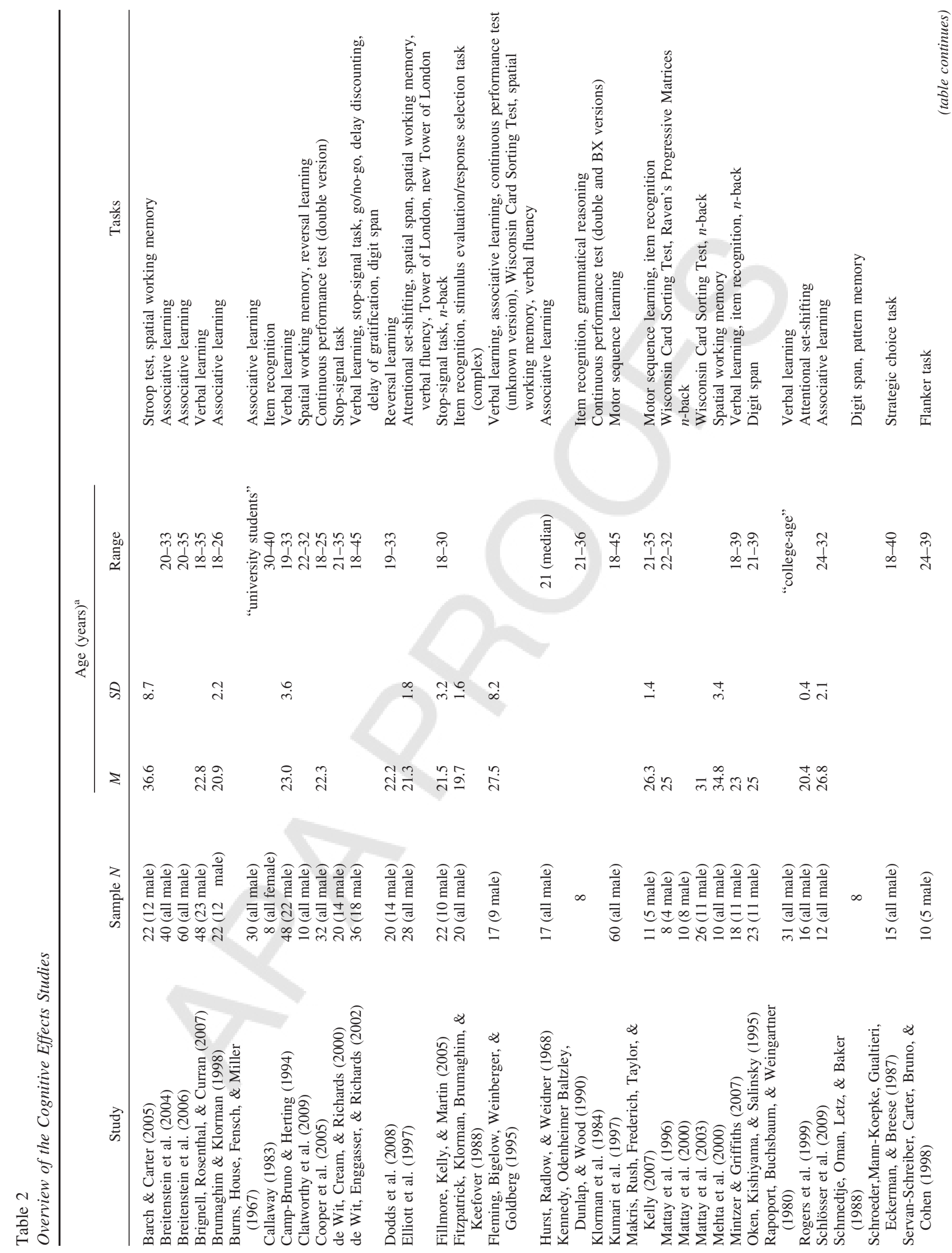


T3,AQ:3

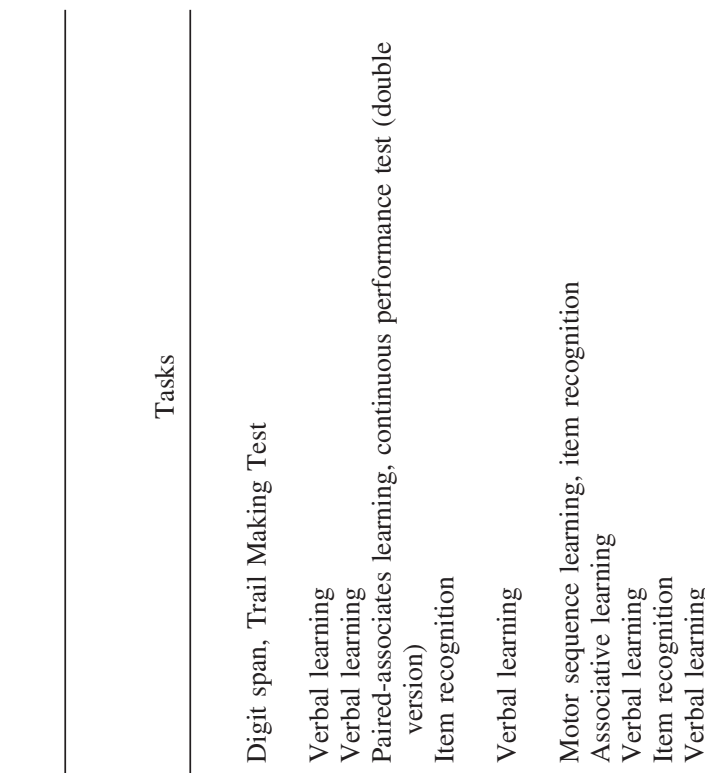

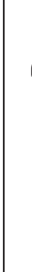$$
\text { 2ิ }
$$

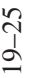<smiles>C1CC[Te]C1</smiles>$$
\hat{\imath}
$$$$
\stackrel{m}{\frac{n}{1}}
$$
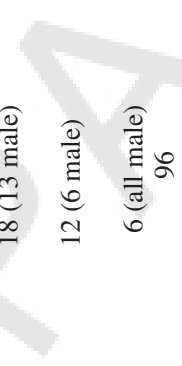

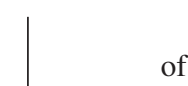

Table 3 lists the results of 24 tasks from 22 articles on the effects of d-AMP or MPH on learning, assessed by a variety of declarative and nondeclarative memory tasks. Results for the 24 tasks are evenly split between enhanced learning and null results, but they yield a clearer pattern when the nature of the learning task and the retention interval are taken into account. In general, with single exposures of verbal material, no benefits are seen immediately following learning, but later recall and recognition are enhanced. Of the six articles reporting on memory performance (CampBruno \& Herting, 1994; Fleming, Bigelow, Weinberger, \& Goldberg, 1995; Rapoport, Busbaum, \& Weingartner, 1980; Soetens, D'Hooge, \& Hueting, 1993; Unrug, Coenen, \& van Luijtelaar, 1997; Zeeuws \& Soetens 2007), encompassing eight separate experiments, only one of the experiments yielded significant memory enhancement at short delays (Rapoport et al., 1980). In contrast, retention was reliably enhanced by d-AMP when subjects were tested after longer delays, with recall improved after $1 \mathrm{hr}$ through 1 week (Soetens, Casaer, D’Hooge, \& Hueting, 1995; Soetens et al., 1993; Zeeuws \& Soetens, 2007). Recognition improved after 1 week in one study (Soetens et al., 1995), while another found recognition improved after $2 \mathrm{hr}$ (Mintzer \& Griffiths, 2007). The one long-term memory study to examine the effects of MPH found a borderline-significant reduction in errors when subjects answered questions about a story (accompanied by slides) presented 1 week before (Brignell, Rosenthal, \& Curran, 2007).

Enhanced learning was also observed in two studies that involved multiple repeated encoding opportunities. Camp-Bruno and Herting (1994) found MPH enhanced summed recall in the Buschke Selective Reminding Test (Buschke, 1973; Buschke \& Fuld, 1974) when 1-hr and 2-hr delays were combined, although individually only the 2-hr delay approached significance. Likewise, de Wit, Enggasser, and Richards (2002) found no effect of d-AMP on the Hopkins Verbal Learning Test (Brandt, 1991) after a 25-min delay. Willett (1962) tested rote learning of nonsense syllables with repeated presentations, and his results indicate that d-AMP decreased the number of trials needed to reach criterion.

In paired-associates learning, subjects are presented with pairs of stimuli and must learn to recall the second item of the pair when presented with the first. For these tasks, as with tasks involving memory for individual items, there is a trend for stimulants to enhance performance with longer delays. For immediate measures of learning, no effects of d-AMP or MPH were observed by Brumaghim and Klorman (1998); Fleming et al. (1995); Hurst, Radlow, and Weidner (1968); or Strauss et al. (1984). However, when Hurst et al.'s subjects were tested a week later, they recalled more if their initial learning had been carried out with d-AMP than with placebo. Weitzner (1965) assessed paired-associates learning with an immediate cued-recall test and found facilitation when the associate word was semantically related to the cue, provided it was not also related to other cue words. Finally, Burns, House, French, and Miller (1967) found a borderline-significant impairment of performance with d-AMP on a nonverbal associative learning task.

The information learned in the tasks reviewed so far was explicit, declarative, and consistent within each experiment. In contrast, probabilistic and procedural learning tasks require the subject to gradually extract a regularity in the associations among stimuli from multiple presentations in which the correct associations are only presented some of the time, with incorrect associations also 


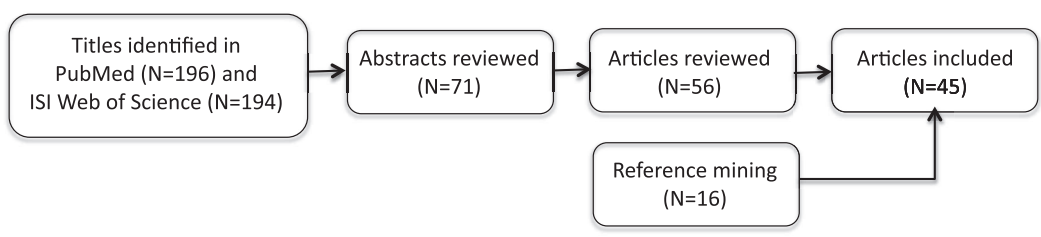

Figure 2. Flow diagram of cognitive neuroscience literature search completed July 2, 2010. Search terms were dextroamphetamine, Aderrall, methylphenidate, or Ritalin, and cognitive, cognition, learning, memory, or executive function, and healthy or normal. Stages of subsequent review used the information contained in the titles, abstracts, and articles to determine whether articles reported studies meeting the inclusion criteria stated in the text.

presented. Findings are mixed in these tasks. Breitenstein and colleagues $(2004,2006)$ showed subjects drawings of common objects accompanied by nonsense word sounds in training sessions that extended over multiple days. They found faster learning of the to-be-learned, higher probability pairings between sessions (consistent with enhanced retention over longer delays). Breitenstein et al. (2004) found that this enhancement remained a year later. Schlösser et al. (2009) tested subjects' probabilistic learning ability in the context of a functional magnetic resonance imaging (fMRI) study, comparing performance and brain activation with MPH and placebo. MPH did not affect learning performance as measured by accuracy. Although subjects were overall faster in responding on $\mathrm{MPH}$, this difference was independent of the difficulty of the learning task, and the authors accordingly attributed it to response processes rather than learning.

Two additional studies assessed the effects of d-AMP on visualmotor sequence learning, a form of nondeclarative, procedural learning, and found no effect (Kumari et al., 1997; Makris, Rush, Frederich, Taylor, \& Kelly, 2007). In a related experimental paradigm, Ward, Kelly, Foltin, and Fischman (1997) assessed the effect of d-AMP on the learning of motor sequences from immediate feedback and also failed to find an effect.

A provisional conclusion about the effects of stimulants on learning is that they do help with the consolidation of declarative learning, with effect sizes varying widely from small to large depending on the task and individual study. Indeed, as a practical matter, stimulants may be more helpful than many of the laboratory tasks indicate, given the apparent dependence of enhancement on length of delay before testing. Although, as a matter of convenience, experimenters tend to test memory for learned material soon after the learning, this method has not generally demonstrated stimulant-enhanced learning. However, when longer periods intervene between learning and test, a more robust enhancement effect can be seen. Note that the persistence of the enhancement effect well past the time of drug action implies that state-dependent learning is not responsible. In general, long-term effects on learning are of greater practical value to people. Even students cramming for exams need to retain information for more than an hour or two. We therefore conclude that stimulant medication does enhance learning in ways that may be useful in the real world.

\section{Do Prescription Stimulants Enhance Working Memory?}

In contrast to the types of memory discussed in the previous section, which are long-lasting and formed as a result of learning, working memory is a temporary store of information. Working memory has been studied extensively by cognitive psychologists and cognitive neuroscientists because of its role in executive function. It has been likened to an internal scratch pad; by holding information in working memory, one keeps it available to consult and manipulate in the service of performing tasks as diverse as parsing a sentence and planning a route through the environment. Presumably for this reason, working memory ability correlates with measures of general intelligence (Friedman et al., 2006). The possibility of enhancing working memory ability is therefore of potential real-world interest.

Many laboratory tasks have been developed to study working memory, each of which taxes to varying degrees aspects such as the overall capacity of working memory, its persistence over time, and its resistance to interference either from task-irrelevant stimuli or among the items to be retained in working memory (i.e., cross-talk). Tasks also vary in the types of information to be retained in working memory, for example, verbal or spatial information. The question of which of these task differences correspond to differences between distinct working memory systems and which correspond to different ways of using a single underlying system is a matter of debate (e.g., D'Esposito, Postle, \& Rypma, 2000; Owen, 2000). For the present purpose, we ignore this question and simply ask, Do MPH and d-AMP affect performance in the wide array of tasks that have been taken to operationalize working memory? If the literature does not yield a unanimous answer to this question, then what factors might be critical in determining whether stimulant effects are manifest?

Table 4 lists the results of 27 tasks from 23 articles on the effects T4,AQ:4 of d-AMP or MPH on working memory. The oldest and most commonly used type of working memory task in this literature is the Sternberg short-term memory scanning paradigm (Sternberg, 1966), in which subjects hold a set of items (typically letters or numbers) in working memory and are then presented with probe items, to which they must respond "yes" (in the set) or "no" (not in the set). The size of the set, and hence the working memory demand, is sometimes varied, and the set itself may be varied from trial to trial to maximize working memory demands or may remain fixed over a block of trials. Taken together, the studies that have used a version of this task to test the effects of MPH and d-AMP on working memory have found mixed and somewhat ambiguous results. No pattern is apparent concerning the specific version of the task or the specific drug. Four studies found no effect (Callaway, 1983; Kennedy, Odenheimer, Baltzley, Dunlap, \& Wood, 1990; Mintzer \& Griffiths, 2007; Tipper et al., 2005), three found 


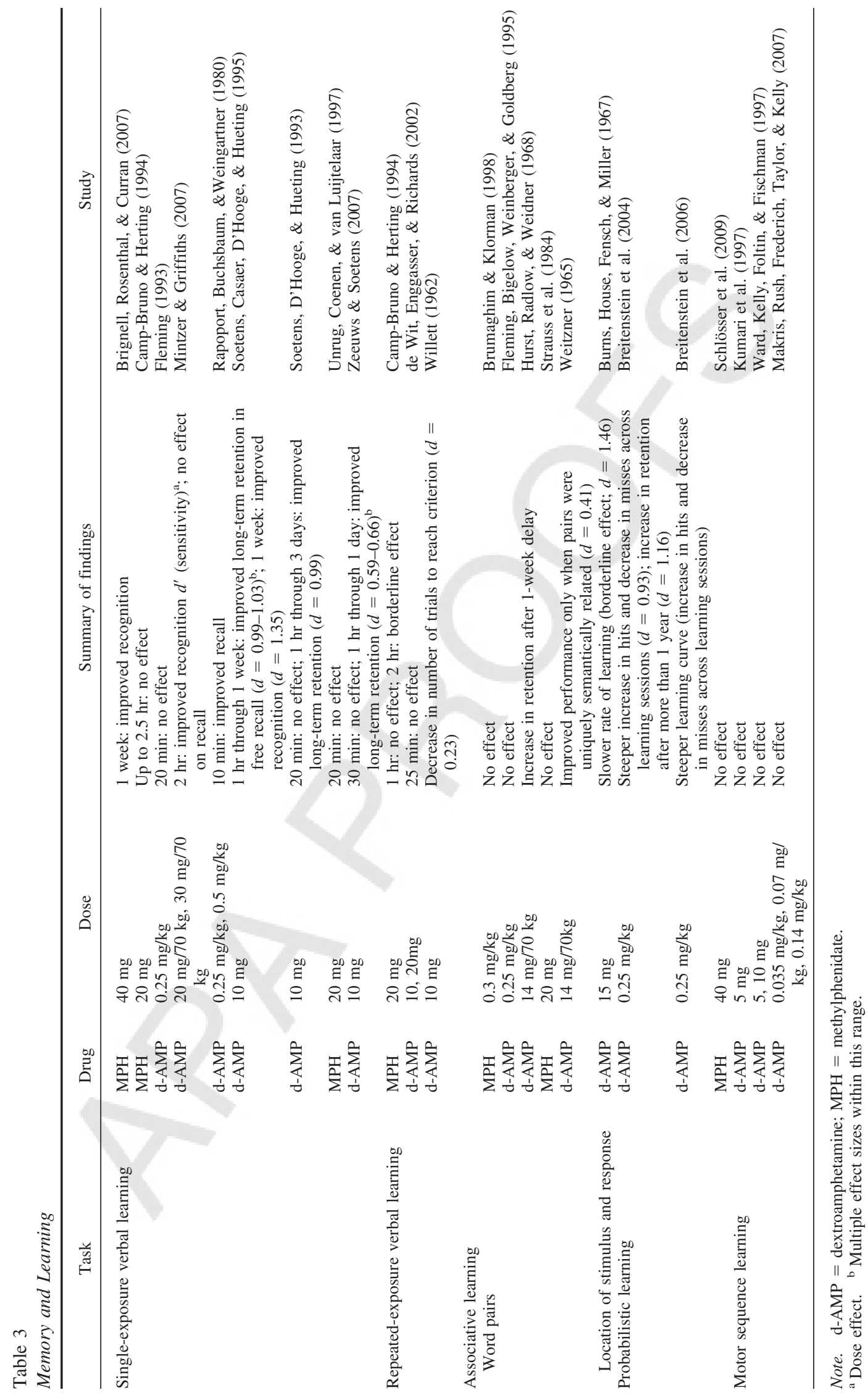


ARE PRESCRIPTION STIMULANTS “SMART PILLS”?

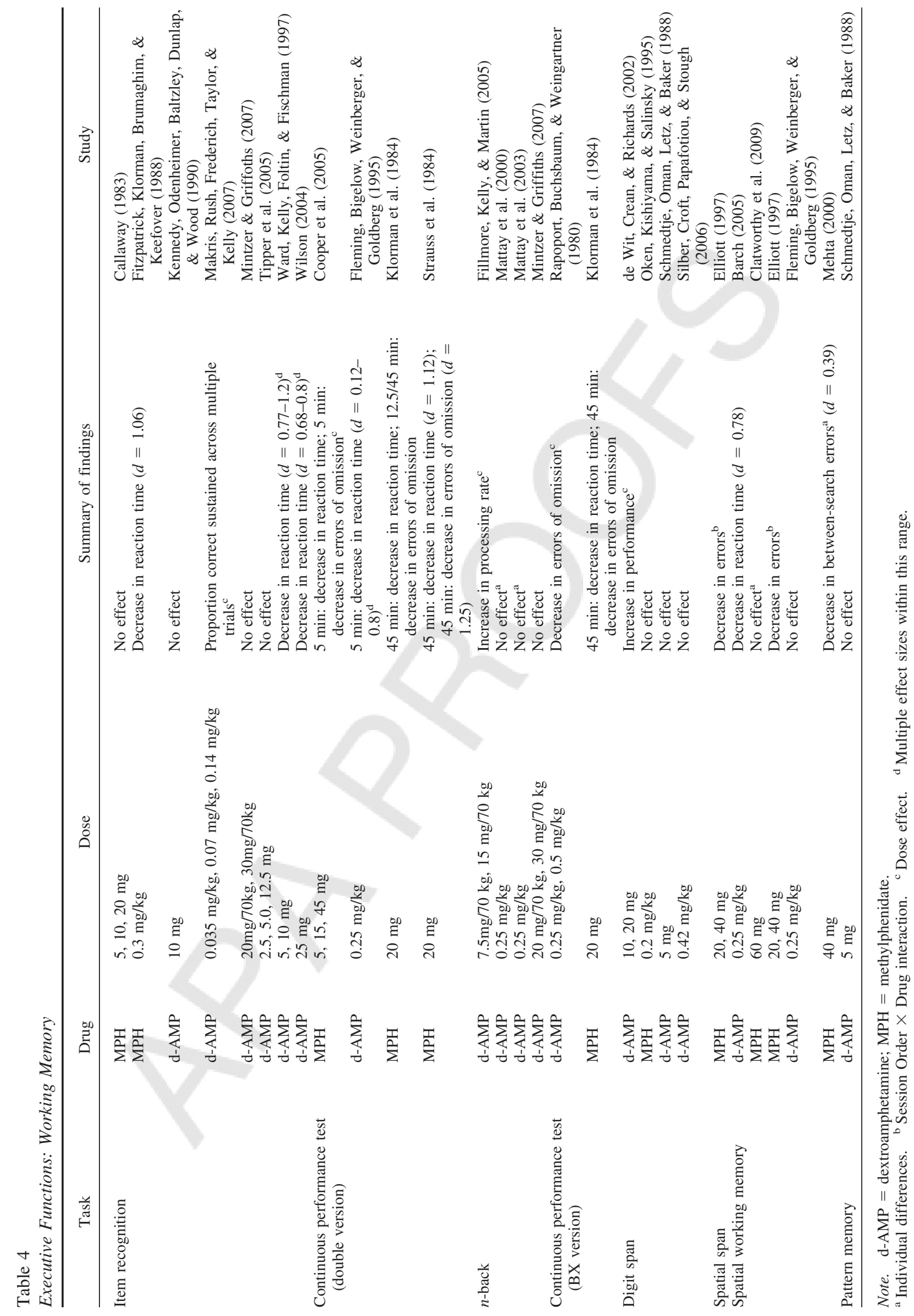


faster responses with the drugs (Fitzpatrick, Klorman, Brumaghim, \& Keefover, 1988; Ward et al., 1997; Wilson et al., 1971), and one found higher accuracy in some testing sessions at some dosages, but no main effect of drug (Makris et al., 2007). The meaningfulness of the increased speed of responding is uncertain, given that it could reflect speeding of general response processes rather than working memory-related processes. Aspects of the results of two studies suggest that the effects are likely due to processes other than working memory: Wilson et al. (1971) reported comparable speeding in a simple task without working memory demands, and Tipper et al. (2005) reported comparable speeding across set sizes.

Another common working memory task is the $n$-back task, which requires the subject to view a series of items (usually letters) and decide whether the current item is identical to the one presented $n$ items back. This task taxes working memory because the previous items must be held in working memory to be compared with the current item. The easiest version of this is a 1-back task, which is also called a double continuous performance task (CPT) because the subject is continuously monitoring for a repeat or double. Three studies examined the effects of MPH on working memory ability as measured by the 1-back task, and all found enhancement of performance in the form of reduced errors of omission (Cooper et al., 2005; Klorman et al., 1984; Strauss et al., 1984). Fleming et al. (1995) tested the effects of d-AMP on a 5-min CPT and found a decrease in reaction time, but did not specify which version of the CPT was used.

The data from 2-back and 3-back tasks are more complex. Three studies examined performance in these more challenging tasks and found no effect of d-AMP on average performance (Mattay et al., 2000, 2003; Mintzer \& Griffiths, 2007). However, in at least two of the studies, the overall null result reflected a mixture of reliably enhancing and impairing effects. Mattay et al. (2000) examined the performance of subjects with better and worse working memory capacity separately and found that subjects whose performance on placebo was low performed better on d-AMP, whereas subjects whose performance on placebo was high were unaffected by d-AMP on the 2-back and impaired on the 3-back tasks. Mattay et al. (2003) replicated this general pattern of data with subjects divided according to genotype. The specific gene of interest codes for the production of Catechol-O-methyltransferase (COMT), an enzyme that breaks down dopamine and norepinephrine. A common polymorphism determines the activity of the enzyme, with a substitution of methionine for valine at Codon 158 resulting in a less active form of COMT. The met allele is thus associated with less breakdown of dopamine and hence higher levels of synaptic dopamine than the val allele. Mattay et al. (2003) found that subjects who were homozygous for the val allele were able to perform the $n$-back faster with d-AMP; those homozygous for met were not helped by the drug and became significantly less accurate in the 3-back condition with d-AMP. In the case of the third study finding no overall effect, analyses of individual differences were not reported (Mintzer \& Griffiths, 2007).

A related task is the $\mathrm{B}-\mathrm{X}$ version of the CPT, in which subjects must respond when an $\mathrm{X}$ appears only if it was preceded by a $\mathrm{B}$. As in the 1-back task, the subject must retain the previous trial's letter in working memory because it determines the subject's response to the current letter. In this case, when the current letter is an X, then the subject should respond only if the previous letter was a B. Two studies examined stimulant effects in this task.
Rapoport et al. (1980) found that d-AMP reduced errors of omission in the longer of two test sessions, and Klorman et al. (1984) found that MPH reduced errors of omission and response time.

Another classic approach to the assessment of working memory is the span task, in which a series of items is presented to the subject for repetition, transcription, or recognition. The longest series that can be reproduced accurately is called the forward span and is a measure of working memory capacity. The ability to reproduce the series in reverse order is tested in backward span tasks and is a more stringent test of working memory capacity and perhaps other working memory functions as well. The digit span task from the Wechsler IQ test was used in four studies of stim- AQ: 5 ulant effects on working memory. One study showed that d-AMP increased digit span (de Wit et al., 2002), and three found no effects of d-AMP or MPH (Oken, Kishiyama, \& Salinsky, 1995; Schmedtje, Oman, Letz, \& Baker, 1988; Silber, Croft, Papafotiou, $\&$ Stough, 2006). A spatial span task, in which subjects must retain and reproduce the order in which boxes in a scattered spatial arrangement change color, was used by Elliott et al. (1997) to assess the effects of MPH on working memory. For subjects in the group receiving placebo first, MPH increased spatial span. However, for the subjects who received MPH first, there was a nonsignificant opposite trend. The group difference in drug effect is not easily explained. The authors noted that the subjects in the first group performed at an overall lower level, and so, this may be another manifestation of the trend for a larger enhancement effect for less able subjects.

Several studies have assessed the effect of MPH and d-AMP on tasks tapping various other aspects of spatial working memory. Three used the spatial working memory task from the CANTAB battery of neuropsychological tests (Sahakian \& Owen, 1992). In this task, subjects search for a target at different locations on a screen. Subjects are told that locations containing a target in previous trials will not contain a target in future trials. Efficient performance therefore requires remembering and avoiding these locations in addition to remembering and avoiding locations already searched within a trial. Mehta et al. (2000) found evidence of greater accuracy with MPH, and Elliott et al. (1997) found a trend for the same. In Mehta et al.'s study, this effect depended on subjects' working memory ability: the lower a subject's score on placebo, the greater the improvement on MPH. In Elliott et al.'s study, MPH enhanced performance for the group of subjects who received the placebo first and made little difference for the other group. The reason for this difference is unclear, but as mentioned above, this may reflect ability differences between the groups. More recently, Clatworthy et al. (2009) undertook a positron emission tomography (PET) study of MPH effects on two tasks, one of which was the CANTAB spatial working memory task. They failed to find consistent effects of MPH on working memory performance but did find a systematic relation between the performance effect of the drug in each individual and its effect on individuals' dopamine activity in the ventral striatum.

Two additional studies used other spatial working memory tasks. Barch and Carter (2005) required subjects to maintain one of 18 locations on the perimeter of a circle in working memory and then report the name of the letter that appeared there in a similarly arranged circle of letters. d-AMP caused a speeding of responses but no change in accuracy. Fleming et al. (1995) referred to a spatial delay response task, with no further description or citation. 
They reported no effect of d-AMP in the task except in the zero-delay condition (which presumably places minimal demand on working memory).

Finally, Schmedtje et al. (1988) used a delayed matching task in which one random pattern of filled squares in a $10 \times 10$ matrix must be held in working memory and compared with another and judged same or different. No effect was observed with a fairly low dose of d-AMP.

In sum, the evidence concerning stimulant effects of working memory is mixed, with some findings of enhancement and some null results, although no findings of overall performance impairment. A few studies showed greater enhancement for less able participants, including two studies reporting overall null results. When significant effects have been found, their sizes vary from small to large, as shown in Table 4. Taken together, these results suggest that stimulants probably do enhance working memory, at least for some individuals in some task contexts, although the effects are not so large or reliable as to be observable in all or even most working memory studies.

\section{Do Prescription Stimulants Enhance Cognitive Control?}

Cognitive control is a broad concept that refers to guidance of cognitive processes in situations where the most natural, automatic, or available action is not necessarily the correct one. Such situations typically evoke a strong inclination to respond but require people to resist responding, or they evoke a strong inclination to carry out one type of action but require a different type of action. The sources of these inclinations that must be overridden are various and include overlearning (e.g., the overlearned tendency to read printed words in the Stroop task), priming by recent practice (e.g., the tendency to respond in the go/no-go task when the majority of the trials are go trials, or the tendency to continue sorting cards according to the previously correct dimension in the Wisconsin Card Sorting Test [WCST]; Grant \& Berg, 1948) and perceptual salience (e.g., the tendency to respond to the numerous flanker stimuli as opposed to the single target stimulus in the flanker task). For the sake of inclusiveness, we also consider the results of studies of reward processing in this section, in which the response tendency to be overridden comes from the desire to have the reward immediately.

Table 5 lists the results of 16 tasks from 13 articles on the effects of d-AMP or MPH on cognitive control. One of the simplest tasks used to study cognitive control is the go/no-go task. Subjects are instructed to press a button as quickly as possible for one stimulus or class of stimuli (go) and to refrain from pressing for another stimulus or class of stimuli (no go). De Wit et al. (2002) used a version of this task to measure the effects of d-AMP on subjects' ability to inhibit a response and found enhancement in the form of decreased false alarms (responses to no-go stimuli) and increased speed of correct go responses. They also found that subjects who made the most errors on placebo experienced the greatest enhancement from the drug.

The stop-signal task has been used in a number of laboratories to study the effects of stimulants on cognitive control. In this task, subjects are instructed to respond as quickly as possible by button press to target stimuli except on certain trials, when the target is followed by a stop signal. On those trials, they must try to avoid responding. The stop signal can follow the target stimulus almost immediately, in which case it is fairly easy for subjects to cancel their response, or it can come later, in which case subjects may fail to inhibit their response. The main dependent measure for stopsignal task performance is the stop time, which is the average go reaction time minus the interval between the target and stop signal at which subjects inhibit $50 \%$ of their responses. De Wit and colleagues have published two studies of the effects of d-AMP on this task. De Wit, Crean, and Richards (2000) reported no significant effect of the drug on stop time for their subjects overall but a significant effect on the half of the subjects who were slowest in stopping on the baseline trials. De Wit et al. (2002) found an overall improvement in stop time in addition to replicating their earlier finding that this was primarily the result of enhancement for the subjects who were initially the slowest stoppers. In contrast, Filmore, Kelly, and Martin (2005) used a different measure of cognitive control in this task, simply the number of failures to stop, and reported no effects of d-AMP.

The Stroop task tests the ability to inhibit the overlearned process of reading by presenting color names in colored ink and instructing subjects to either read the word (low need for cognitive control because this is the habitual response to printed words) or name the ink color (high need for cognitive control). Barch and Carter (2005) administered this task to normal control subjects on placebo and d-AMP and found speeding of responses with the drug. However, the speeding was roughly equivalent for the conditions with low and high cognitive control demands, suggesting that the observed facilitation may not have been specific to cognitive control.

As mentioned earlier, cognitive control is needed not only for inhibiting actions, but also for shifting from one kind of action or mental set to another. The WCST taxes cognitive control by requiring the subject to shift from sorting cards by one dimension (e.g., shape) to another (e.g., color); failures of cognitive control in this task are manifest as perseverative errors in which subjects continue sorting by the previously successful dimension. Three studies included the WCST in their investigations of the effects of d-AMP on cognition (Fleming et al., 1995; Mattay et al., 1996, 2003), and none revealed overall effects of facilitation. However, Mattay et al. (2003) subdivided their subjects according to COMT genotype and found differences in both placebo performance and effects of the drug. Subjects who were homozygous for the val allele (associated with lower prefrontal dopamine activity) made more perseverative errors on placebo than other subjects and improved significantly with d-AMP. Subjects who were homozygous for the met allele performed best on placebo and made more errors on d-AMP.

The intradimensional-extradimensional shift task from the CANTAB battery was used in two studies of MPH and measures the ability to shift the response criterion from one dimension to another, as in the WCST, as well as to measure other abilities, including reversal learning, measured by performance in the trials following an intradimensional shift. With an intradimensional shift, the learned association between values of a given stimulus dimension and reward versus no reward is reversed, and participants must learn to reverse their responses accordingly. Elliott et al. (1997) reported finding no effects of the drug on ability to shift among dimensions in the extradimensional shift condition and did not describe performance on the intradimensional shift. Rogers et 

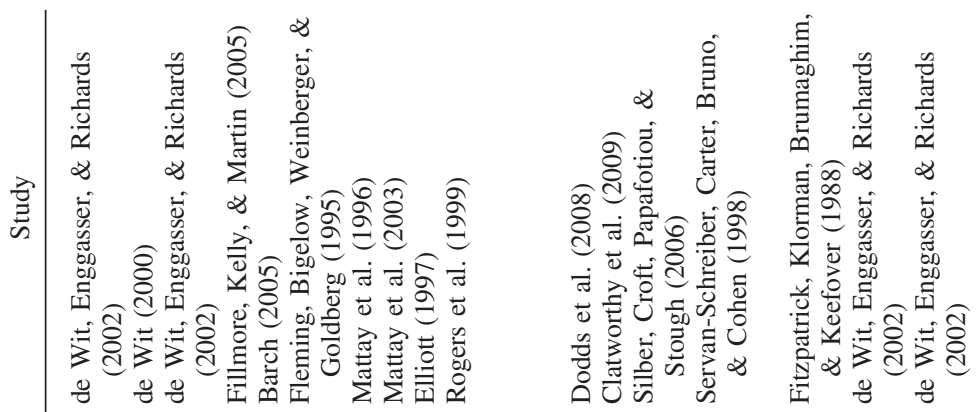

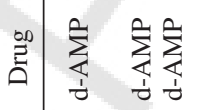

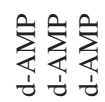

$\hat{\Sigma} \hat{\Sigma}$

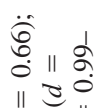

उ

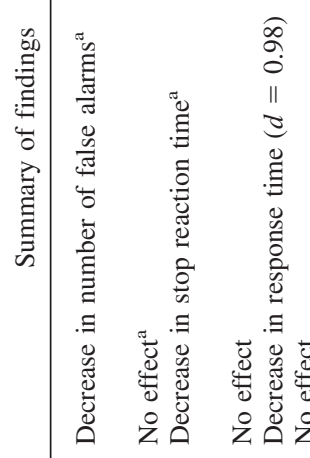

ڤั.

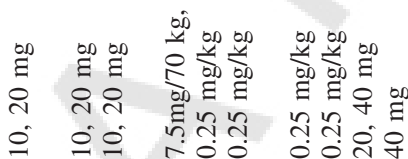

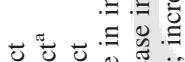

江

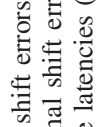

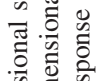

要

害远

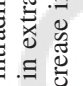

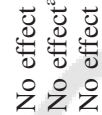

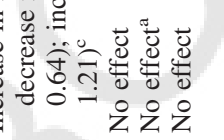

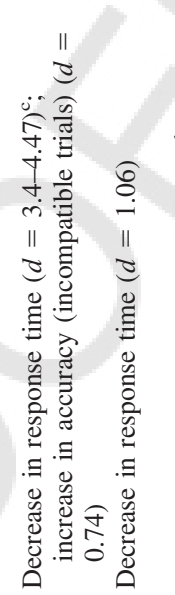

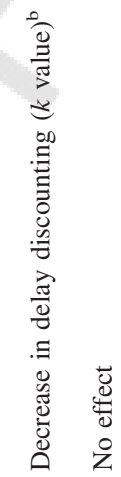

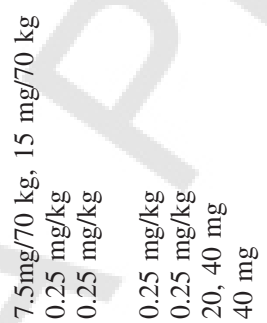

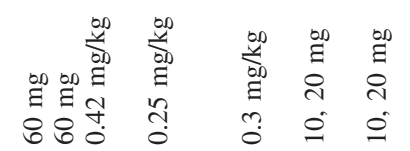

|

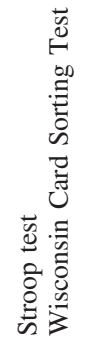

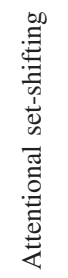
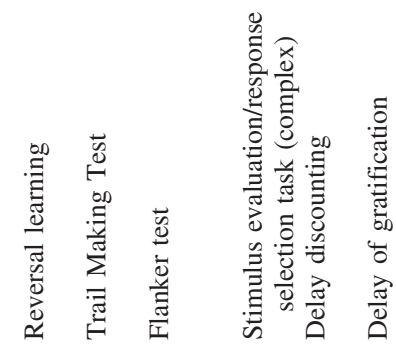

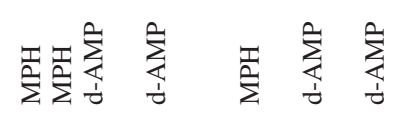

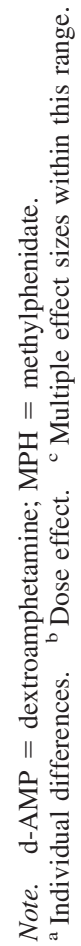


al. (1999) found that accuracy improved but responses slowed with MPH on trials requiring a shift from one dimension to another, which leaves open the question of whether the drug produced net enhancement, interference, or neither on these trials once the tradeoff between speed and accuracy is taken into account. For intradimensional shifts, which require reversal learning, these authors found drug-induced impairment: significantly slower responding accompanied by a borderline-significant impairment of accuracy.

Two studies investigated the effects of MPH on reversal learning in simple two-choice tasks (Clatworthy et al., 2009; Dodds et al., 2008). In these tasks, participants begin by choosing one of two stimuli and, after repeated trials with these stimuli, learn that one is usually rewarded and the other is usually not. The rewarded and nonrewarded stimuli are then reversed, and participants must then learn to choose the new rewarded stimulus. Although each of these studies found functional neuroimaging correlates of the effects of MPH on task-related brain activity (increased blood oxygenation level-dependent signal in frontal and striatal regions associated with task performance found by Dodds et al., 2008, using fMRI and increased dopamine release in the striatum as measured by increased raclopride displacement by Clatworthy et al., 2009, using PET), neither found reliable effects on behavioral performance in these tasks. The one significant result concerning purely behavioral measures was Clatworthy et al.'s (2009) finding that participants who scored higher on a self-report personality measure of impulsivity showed more performance enhancement with MPH. MPH's effect on performance in individuals was also related to its effects on individuals' dopamine activity in specific regions of the caudate nucleus.

The Trail Making Test is a paper-and-pencil neuropsychological test with two parts, one of which requires shifting between stimulus categories. Part A simply requires the subject to connect circled numbers in ascending order. Part B requires the subject to connect circled numbers and letters in an interleaved ascending order $(1, \mathrm{~A}, 2, \mathrm{~B}, 3, \mathrm{C} . .$.$) , a task that places heavier demands on$ cognitive control. Silber et al. (2006) analyzed the effect of d-AMP on Trails A and B and failed to find an effect.

The flanker task is designed to tax cognitive control by requiring subjects to respond based on the identity of a target stimulus ( $\mathrm{H}$ or S) and not the more numerous and visually salient stimuli that flank the target (as in a display such as HHHSHHH). ServanSchreiber, Carter, Bruno, and Cohen (1998) administered the flanker task to subjects on placebo and d-AMP. They found an overall speeding of responses but, more importantly, an increase in accuracy that was disproportionate for the incongruent conditions, that is, the conditions in which the target and flankers did not match and cognitive control was needed.

Perceptual-motor congruency was the basis of a study by Fitzpatrick et al. (1988) in which subjects had to press buttons to indicate the location of a target stimulus in a display. In the simple condition, the left-to-right positions of the buttons are used to indicate the left-to-right positions of the stimuli, a natural mapping that requires little cognitive control. In the rotation condition, the mapping between buttons and stimulus positions is shifted to the right by one and wrapped around, such that the left-most button is used to indicate the right-most position. Cognitive control is needed to resist responding with the other, more natural mapping. $\mathrm{MPH}$ was found to speed responses in this task, and the speeding was disproportionate for the rotation condition, consistent with enhancement of cognitive control.

Finally, two tasks measuring subjects' ability to control their responses to monetary rewards were used by de Wit et al. (2002) to assess the effects of d-AMP. When subjects were offered the choice between waiting $10 \mathrm{~s}$ between button presses for highprobability rewards, which would ultimately result in more money, and pressing a button immediately for lower probability rewards, d-AMP did not affect performance. However, when subjects were offered choices between smaller rewards delivered immediately and larger rewards to be delivered at later times, the normal preference for immediate rewards was weakened by d-AMP. That is, subjects were more able to resist the impulse to choose the immediate reward in favor of the larger reward.

Taken together, the available results are mixed, with slightly more null results than overall positive findings of enhancement and evidence of impairment in one reversal learning task. As the effect sizes listed in Table 5 show, the effects when found are generally substantial. When drug effects were assessed as a function of placebo performance, genotype, or self-reported impulsivity, enhancement was found to be greatest for participants who performed most poorly on placebo, had a COMT genotype associated with poorer executive function, or reported being impulsive in their everyday lives. In sum, the effects of stimulants on cognitive control are not robust, but MPH and d-AMP appear to enhance cognitive control in some tasks for some people, especially those less likely to perform well on cognitive control tasks.

\section{Do Prescription Stimulants Enhance Other Executive Functions?}

Having reviewed the literature on enhancement of working memory and cognitive control, we are left with a small set of studies that seem relevant to executive function but do not fit easily under the previous rubrics and have little else in common with each other.

As shown in Table 6, two of these are fluency tasks, which require the generation of as large a set of unique responses as possible that meet the criteria given in the instructions. Fluency tasks are often considered tests of executive function because they require flexibility and the avoidance of perseveration and because they are often impaired along with other executive functions after prefrontal damage. In verbal fluency, subjects are asked to generate as many words that begin with a specific letter as possible. Neither Fleming et al. (1995), who administered d-AMP, nor Elliott et al. (1997), who administered MPH, found enhancement of verbal fluency. However, Elliott et al. found enhancement on a more complex nonverbal fluency task, the sequence generation task. Subjects were able to touch four squares in more unique orders with MPH than with placebo.

Raven's Progressive Matrices (Raven, 1990) are a nonverbal intelligence test that requires subjects to complete sequences of designs with the appropriate choice from a multiple-choice set. Analogical reasoning is emphasized. Mattay et al. (1996) found that subjects scored higher on such items after d-AMP than placebo.

Two variants of the Towers of London task were used by Elliott et al. (1997) to study the effects of MPH on planning. The object of this task is for subjects to move game pieces from one position 
Table 6

Executive Functions: Other

\begin{tabular}{|c|c|c|c|c|}
\hline Task & Drug & Dose & Summary of findings & Study \\
\hline Verbal fluency & $\begin{array}{l}\text { MPH } \\
\text { d-AMP }\end{array}$ & $\begin{array}{l}20,40 \mathrm{mg} \\
0.25 \mathrm{mg} / \mathrm{kg}\end{array}$ & $\begin{array}{l}\text { No effect } \\
\text { No effect }\end{array}$ & $\begin{array}{l}\text { Elliott (1997) } \\
\text { Fleming, Bigelow, Weinberger, \& } \\
\quad \text { Goldberg (1995) }\end{array}$ \\
\hline Sequence generation & MPH & $20,40 \mathrm{mg}$ & $\begin{array}{l}\text { Increase in number of } \\
\text { sequences generated }^{\text {a }}\end{array}$ & Elliott (1997) \\
\hline Raven's Progressive Matrices & d-AMP & $0.25 \mathrm{mg} / \mathrm{kg}$ & $\begin{array}{l}\text { Increase in percent of correct } \\
\text { responses }(d=1.08)\end{array}$ & Mattay et al. (1996) \\
\hline Tower of London & MPH & $20,40 \mathrm{mg}$ & $\begin{array}{l}\text { Relative decrease in } \\
\text { accuracy } \text { decrease in }^{\mathrm{a}} \text {, decinning latency } \\
\text { pla }^{\mathrm{a}}\end{array}$ & Elliott (1997) \\
\hline New Tower of London & MPH & $20,40 \mathrm{mg}$ & Increase in accuracy ${ }^{\mathrm{a}}$ & Elliott (1997) \\
\hline Grammatical reasoning & d-AMP & $10 \mathrm{mg}$ & No effect & $\begin{array}{l}\text { Kennedy, Odenheimer, Baltzley, } \\
\text { Dunlap, \& Wood (1990) }\end{array}$ \\
\hline Strategic choice task & MPH & $0.15 \mathrm{mg} / \mathrm{kg}, 0.30 \mathrm{mg} / \mathrm{kg}$ & Decrease in changeover rate & $\begin{array}{l}\text { Schroeder, Mann-Koepke, } \\
\text { Gualtieri, Eckerman, \& Breese } \\
\text { (1987) }\end{array}$ \\
\hline
\end{tabular}

Note. $\quad \mathrm{d}$-AMP $=$ dextroamphetamine; $\mathrm{MPH}=$ methylphenidate.

${ }^{\mathrm{a}}$ Session Order $\times$ Drug interaction.

to another while adhering to rules that constrain the ways in which they can move the pieces, thus requiring subjects to plan their moves several steps ahead. Neither version of the task revealed overall effects of the drug, but one version showed impairment for the group that received the drug first, and the other version showed enhancement for the group that received the placebo first.

Kennedy et al. (1990) administered what they termed a grammatical reasoning task to subjects, in which a sentence describing the order of two letters, A and B, is presented along with the letter pair, and subjects must determine whether or not the sentence correctly describes the letter pair. They found no effect of d-AMP on performance of this task.

Schroeder, Mann-Koepke, Gualtieri, Eckerman, and Breese (1987) assessed the performance of subjects on placebo and MPH in a game that allowed subjects to switch between two different sectors seeking targets to shoot. They did not observe an effect of the drug on overall level of performance, but they did find fewer switches between sectors among subjects who took MPH, and perhaps because of this, these subjects did not develop a preference for the more fruitful sector.

Only two of the eight experiments reviewed in this section found that stimulants enhanced performance, on a nonverbal fluency task in one case and in Raven's Progressive Matrices in the other. The small number of studies of any given type makes it difficult to draw general conclusions about the underlying executive function systems that might be influenced.

\section{Summary Regarding Stimulant Effects on Cognition}

The title question, whether prescription stimulants are smart pills, does not find a unanimous answer in the literature. The preponderance of evidence is consistent with enhanced consolidation of long-term declarative memory. For executive function, the overall pattern of evidence is much less clear. Over a third of the findings show no effect on the cognitive processes of healthy nonelderly adults. Of the rest, most show enhancement, although impairment has been reported (e.g., Rogers et al., 1999), and certain subsets of participants may experience impairment (e.g., higher performing participants and/or those homozygous for the met allele of the COMT gene performed worse on drug than placebo; Mattay et al., 2000, 2003). Whereas the overall trend is toward enhancement of executive function, the literature contains many exceptions to this trend. Furthermore, publication bias may lead to underreporting of these exceptions.

Null results are less likely to be published than positive results in any field. In the case of stimulant effects on the cognition of normal healthy subjects, this would have the effect of exaggerating the enhancement potential of stimulants by omitting null results from the published literature. Consistent with the operation of such a bias in the present literature, the null results found in our survey were invariably included in articles reporting the results of multiple tasks or multiple measures of a single task; published singletask studies with exclusively behavioral measures all found enhancement. This suggests that some single-task studies with null results have gone unreported.

Interpreting equivocal findings of cognitive enhancement. How should the mixed results just summarized be interpreted vis-à-vis the cognitive-enhancing potential of prescription stimulants? One possibility is that d-AMP and MPH enhance cognition, including the retention of just-acquired information and some or all forms of executive function, but that the enhancement effect is small. If this were the case, then many of the published studies were underpowered for detecting enhancement, with most samples sizes under 50. It follows that the observed effects would be inconsistent, a mix of positive and null findings.

Brain-imaging studies are consistent with the existence of small effects that are not reliably captured by the behavioral paradigms of the literature reviewed here. Typically with executive function tasks, reduced activation of task-relevant areas is associated with better performance and is interpreted as an indication of higher neural efficiency (e.g., Haier, Siegel, Tang, Abel, \& Buchsbaum, 1992). Several imaging studies showed effects of stimulants on task-related activation while failing to find effects on cognitive 
performance. Although changes in brain activation do not necessarily imply functional cognitive changes, they are certainly suggestive and may well be more sensitive than behavioral measures. Evidence of this comes from a study of COMT variation and executive function. Egan and colleagues (2001) found a genetic effect on executive function in an fMRI study with sample sizes as small as 11 but did not find behavioral effects in these samples. The genetic effect on behavior was demonstrated in a separate study with over a hundred participants. In sum, d-AMP and MPH measurably affect the activation of task-relevant brain regions when participants' task performance does not differ. This is consistent with the hypothesis (although by no means positive proof) that stimulants exert a true cognitive-enhancing effect that is simply too small to be detected in many studies.

If stimulants truly enhance cognition but do so to only a small degree, this raises the question of whether small effects are of practical use in the real world. Under some circumstances, the answer would undoubtedly be yes. Success in academic and occupational competitions often hinges on the difference between being at the top or merely near the top. A scholarship or a promotion that can go to only one person will not benefit the runner-up at all. Hence, even a small edge in the competition can be important.

Another interpretation of the mixed results in the literature is that, in some cases at least, individual differences in response to stimulants have led to null results when some participants in the sample are in fact enhanced and others are not. This possibility is not inconsistent with the previously mentioned ones; both could be at work. Evidence has already been reviewed that ability level, personality, and COMT genotype modulate the effect of stimulants, although most studies in the literature have not broken their samples down along these dimensions. There may well be other as-yet-unexamined individual characteristics that determine drug response. The equivocal nature of the current literature may reflect a mixture of substantial cognitive-enhancement effects for some individuals, diluted by null effects or even counteracted by impairment in others.

An additional complexity, related to individual differences, concerns dosage. This factor, which varies across studies and may be fixed or determined by participant body weight within a study, undoubtedly influences the cognitive effects of stimulant drugs. Furthermore, single-unit recordings with animals and, more recently, imaging of humans indicate that the effects of stimulant dose are nonmonotonic; increases enhance prefrontal function only up to a point, with further increases impairing function (e.g., Arnsten, 1998; Mattay et al., 2003; Robbins \& Arnsten, 2009). Yet additional complexity comes from the fact that the optimal dosage depends on the same kinds of individual characteristics just discussed and on the task (Mattay et al., 2003).

Taken together, these considerations suggest that the cognitive effects of stimulants for any individual in any task will vary based on dosage and will not easily be predicted on the basis of data from other individuals or other tasks. Optimizing the cognitive effects of a stimulant would therefore require, in effect, a search through a high-dimensional space whose dimensions are dose; individual characteristics such as genetic, personality, and ability levels; and task characteristics. The mixed results in the current literature may be due to the lack of systematic optimization.

\section{Outstanding Issues}

\section{Open Questions Concerning the Cognitive Neuroscience of Cognitive Enhancement}

Given the size of the literature just reviewed, it is surprising that so many basic questions remain open. Although d-AMP and MPH appear to enhance retention of recently learned information and, in at least some individuals, also enhance working memory and cognitive control, there remains great uncertainty regarding the size and robustness of these effects and their dependence on dosage, individual differences, and specifics of the task.

In addition, while the laboratory research reviewed here is of interest concerning the effects of stimulant drugs on specific cognitive processes, it does not tell us about the effects on cognition in the real world. How do these drugs affect academic performance when used by students? How do they affect the total knowledge and understanding that students take with them from a course? How do they affect various aspects of occupational performance? Similar questions have been addressed in relation to students and workers with ADHD (Barbaresi, Katusic, Colligan, Weaver, \& Jacobsen, 2007; Halmøy, Fasmer, Gillberg, \& Haavik, 2009; see also Advokat, 2010) but have yet to be addressed in the context of cognitive enhancement of normal individuals.

Another empirical question concerns the effects of stimulants on motivation, which can affect academic and occupational performance independent of cognitive ability. Volkow and colleagues (2004) showed that MPH increased participants' self-rated interest in a relatively dull mathematical task. This is consistent with student reports that prescription stimulants make schoolwork seem more interesting (e.g., DeSantis et al., 2008). To what extent are the motivational effects of prescription stimulants distinct from their cognitive effects, and to what extent might they be more robust to differences in individual traits, dosage, and task? Are the motivational effects of stimulants responsible for their usefulness when taken by normal healthy individuals for cognitive enhancement?

Finally, all of the questions raised here in relation to MPH and d-AMP can also be asked about newer drugs and even about nonpharmacological methods of cognitive enhancement. An example of a newer drug with cognitive-enhancing potential is modafinil. Originally marketed as a therapy for narcolepsy, it is widely used off label for other purposes (Vastag, 2004), and a limited literature on its cognitive effects suggests some promise as a cognitive enhancer for normal healthy people (see Minzenberg \& Carter, 2008, for a review).

Nondrug cognitive-enhancement methods include the high tech and the low. An example of the former is transcranial magnetic stimulation (TMS), whereby weak currents are induced in specific brain areas by magnetic fields generated outside the head. TMS is currently being explored as a therapeutic modality for neuropsychiatric conditions as diverse as depression and ADHD and is capable of enhancing the cognition of normal healthy people (e.g., Kirschen, Davis-Ratner, Jerde, Schraedley-Desmond, \& Desmond, 2006). An older technique, transcranial direct current stimulation (tDCS), has become the subject of renewed research interest and has proven capable of enhancing the cognitive performance of normal healthy individuals in a variety of tasks. For example, Flöel, Rösser, Michka, Knecht, and Breitenstein (2008) reported 
enhancement of learning and Dockery, Hueckel-Weng, Birbaumer, and Plewnia (2009) reported enhancement of planning with tDCS.

Low-tech methods of cognitive enhancement include many components of what has traditionally been viewed as a healthy lifestyle, such as exercise, good nutrition, adequate sleep, and stress management. These low-tech methods nevertheless belong in a discussion of brain enhancement because, in addition to benefiting cognitive performance, their effects on brain function have been demonstrated (Almeida et al., 2002; Boonstra, Stins, Daffertshofer, \& Beek, 2007; Hillman, Erickson, \& Kramer, 2008; Lutz, Slagter, Dunne, \& Davidson, 2008; Van Dongen, Maislin, Mullington, \& Dinges, 2003).

\section{Open Questions Concerning the Epidemiology of Cognitive Enhancement}

It is known that American college students have embraced cognitive enhancement, and some information exists about the demographics of the students most likely to practice cognitive enhancement with prescription stimulants. Outside of this narrow segment of the population, very little is known. What happens when students graduate and enter the world of work? Do they continue using prescription stimulants for cognitive enhancement in their first jobs and beyond? How might the answer to this question depend on occupation? For those who stay on campus to pursue graduate or professional education, what happens to patterns of use? To what extent do college graduates who did not use stimulants as students begin to use them for cognitive enhancement later in their careers? To what extent do workers without college degrees use stimulants to enhance job performance? How do the answers to these questions differ for countries outside of North America, where the studies of Table 1 were carried out?

Another important epidemiological question about the use of prescription stimulants for cognitive enhancement concerns the risk of dependence. MPH and d-AMP both have high potential for abuse and addiction related to their effects on brain systems involved in motivation. On the basis of their reanalysis of NSDUH data sets from 2000 to 2002, Kroutil and colleagues (2006) estimated that almost one in 20 nonmedical users of prescription ADHD medications meets criteria for dependence or abuse. This sobering estimate is based on a survey of all nonmedical users. The immediate and long-term risks to individuals seeking cognitive enhancement remain unknown.

An entirely different set of questions concerns cognitive enhancement in younger students, including elementary school and even preschool children. Some children can function adequately in school without stimulants but perform better with them; medicating such children could be considered a form of cognitive enhancement. How often does this occur? What are the roles and motives of parents, teachers, and pediatricians in these cases? These questions have been discussed elsewhere and deserve continued attention (Diller, 1996; Singh \& Keller, 2010).

Regarding other methods of cognitive enhancement, little systematic research has been done on their prevalence among healthy people for the purpose of cognitive enhancement. One exploratory survey found evidence of modafinil use by people seeking cognitive enhancement (Maher, 2008), and anecdotal reports of this can be found online (e.g., Arrington, 2008; Madrigal, 2008). Whereas TMS requires expensive equipment, tDCS can be implemented with inexpensive and widely available materials, and online chatter indicates that some are experimenting with this method.

\section{Conclusions}

The goal of this article has been to synthesize what is known about the use of prescription stimulants for cognitive enhancement and what is known about the cognitive effects of these drugs. We have eschewed discussion of ethical issues in favor of simply trying to get the facts straight. Although ethical issues cannot be decided on the basis of facts alone, neither can they be decided without relevant facts. Personal and societal values will dictate whether success through sheer effort is as good as success with pharmacologic help, whether the freedom to alter one's own brain chemistry is more important than the right to compete on a level playing field at school and work, and how much risk of dependence is too much risk. Yet these positions cannot be translated into ethical decisions in the real world without considerable empirical knowledge. Do the drugs actually improve cognition? Under what circumstances and for whom? Who will be using them and for what purposes? What are the mental and physical health risks for frequent cognitive-enhancement users? For occasional users?

The one indisputable finding from the literature so far is that many people are seeking cognitive enhancement. Beyond that, the literature yields only partial and tentative answers to the questions just raised. Given the potential impact of cognitive enhancement on society, more research is needed. For research on the epidemiology of cognitive enhancement, studies focused on the cognitiveenhancement practices and experiences of students and nonstudent workers are needed. For research on the cognitive effects of prescription stimulants, larger samples are needed. Only with substantially larger samples will it be possible to assess small but potentially important benefits, as well as risks, and to distinguish individual differences in drug response. Large samples would also be required to compare these effects to the cognitive effects of improved sleep, exercise, nutrition, and stress management. To include more ecologically valid measures of cognition in academic and work environments would in addition require the equivalent of a large clinical trial.

Unfortunately, cognitive enhancement falls between the stools of research funding, which makes it unlikely that such research programs will be carried out. Disease-oriented funders will, by definition, not support research on normal healthy individuals. The topic intersects with drug abuse research only in the assessment of risk, leaving out the study of potential benefits, as well as the comparative benefits of other enhancement methods. As a fundamentally applied research question, it will not qualify for support by funders of basic science. The pharmaceutical industry would be expected to support such research only if cognitive enhancement were to be considered a legitimate indication by the FDA, which we hope would happen only after considerably more research has illuminated its risks, benefits, and societal impact. Even then, industry would have little incentive to delve into all of the issues raised here, including the comparison of drug effects to nonpharmaceutical means of enhancing cognition.

The absence of a suitable home for this needed research on the current research funding landscape exemplifies a more general problem emerging now, as applications of neuroscience begin to 
reach out of the clinical setting and into classrooms, offices, courtrooms, nurseries, marketplaces, and battlefields (Farah, in press). Most of the longstanding sources of public support for neuroscience research are dedicated to basic research or medical applications. As neuroscience is increasingly applied to solving problems outside the medical realm, it loses access to public funding. The result is products and systems reaching the public with less than adequate information about effectiveness and/or safety. Examples include cognitive enhancement with prescription stimulants, event-related potential and fMRI-based lie detection, neuroscience-based educational software, and anti-brain-aging computer programs. Research and development in nonmedical neuroscience are now primarily the responsibility of private corporations, which have an interest in promoting their products. Greater public support of nonmedical neuroscience research, including methods of cognitive enhancement, will encourage greater knowledge and transparency concerning the efficacy and safety of these products and will encourage the development of products based on social value rather than profit value.

\section{References}

Advokat, C. (2010). What are the cognitive effects of stimulant medication? Emphasis on adults with attention-deficit/hyperactivity disorder. Neuroscience and Biobehavioral Reviews, 34, 1256-1266. doi:10.1016/ j.neubiorev.2010.03.006

Almeida, S. S., Duntas, L. H., Dye, L., Nunes, M. L., Prasad, C., Rocha, J. B. T., ... Guedes, R. C. A. (2002). Nutrition and brain function: A multidisciplinary virtual symposium. Nutritional Neuroscience, 5, 311320. doi:10.1080/1028415021000033776

Arnsten, A. F. T. (1998). Catecholamine modulation of prefrontal cortical cognitive function. Trends in Cognitive Sciences, 2, 436-447. doi: 10.1016/S1364-6613(98)01240-6

Arria, A. M., O'Grady, K. E., Caldeira, K. M., Vincent, K. B., \& Wish, E. D. (2008). Nonmedical use of prescription stimulants and analgesics: Associations with social and academic behaviors among college students. Pharmacotherapy, 38, 1045-1060. doi:10.1592/phco.28.2.156

Arrington, M. (2008, July 15). How many Silicon Valley startup executives are hopped up on Provigil? TechCrunch. Retrieved from http:// techcrunch.com/2008/07/15/how-many-of-our-startup-executives-arehopped-up-on-provigil/

Babcock, Q., \& Byrne, T. (2000). Student perceptions of methylphenidate abuse at a public liberal arts college. Journal of American College Health, 49, 143-145. doi:10.1080/07448480009596296

Barbaresi, W. J., Katusic, S. K., Colligan, R. C., Weaver, A. L., \& Jacobsen, S. J. (2007). Modifiers of long-term school outcomes for children with attention-deficit/hyperactivity disorder: Does treatment with stimulant medication make a difference? Results from a populationbased study. Journal of Developmental and Behavioral Pediatrics, 28, 274-287. doi:10.1097/DBP.0b013e3180cabc28

Barch, D. M., \& Carter, C. S. (2005). Amphetamine improves cognitive function in medicated individuals with schizophrenia and in healthy volunteers. Schizophrenia Research, 77, 43-58.

Barrett, S. P., Darredeau, C., Bordy, L. E., \& Pihl, R. O. (2005). Characteristics of methylphenidate misuse in a university student sample. Canadian Journal of Psychiatry/La Revue Canadienne de Psychiatrie, 50, 457-461.

Boonstra, T. W., Stins, J. F., Daffertshofer, A., \& Beek, P. J. (2007). Effects of sleep deprivation on neural functioning: An integrative review. Cellular \& Molecular Life Sciences, 64, 934-946. doi:10.1007/ s00018-007-6457-8

Bostrom, N., \& Sandberg, A. (2009). Cognitive enhancement: Methods, ethics, regulatory challenges. Science and Engineering Ethics, 15, 311341. doi:10.1007/s11948-009-9142-5
Boyd, C. J., \& McCabe, S. E. (2008). Coming to terms with the nonmedical use of prescription medications. Substance Abuse Treatment, Prevention, and Policy, 3:22. doi:10.1186/1747-597X-3-22

Boyd, C. J., McCabe, S. E., Cranford, J. A., \& Young, A. (2006). Adolescents' motivations to abuse prescription medications. Pediatrics, 118, 2472-2480. doi:10.1542/peds.2006-1644

Brandt, J. (1991). The Hopkins Verbal Learning Test: Development of a new memory test with six equivalent forms. Clinical Neuropsychologist, 5, 125-142. doi:10.1080/13854049108403297

Breitenstein, C., Flöel, A., Korsukewitz, C., Wailke, S., Bushuven, S., \& Knecht, S. (2006). A shift of paradigm: From noradrenergic to dopaminergic modulation of learning? Journal of the Neurological Sciences, 248, 42-47. doi:10.1016/j.jns.2006.05.012

Breitenstein, C., Wailke, S., Bushuven, S., Kamping, S., Zwitserlood, P., Ringelstein, E. B., \& Knecht, S. (2004). D-amphetamine boosts language learning independent of its cardiovascular and motor arousing effects. Neuropsychopharmacology, 29, 1704-1714. doi:10.1038/sj.npp.1300464

Brignell, C. M., Rosenthal, J., \& Curran, H. V. (2007). Pharmacological manipulations of arousal and memory for emotional material: Effects of a single dose of methylphenidate or lorazepam. Journal of Psychopharmacology, 21, 673-683. doi:10.1177/0269881107077351

Brumaghim, J. T., \& Klorman, R. (1998). Methylphenidate's effects on paired-associate learning and event-related potentials of young adults. Psychophysiology, 35, 73-85. doi:10.1111/1469-8986.3510073

Burns, J. T., House, R. F., Fensch, F. C., \& Miller, J. G. (1967, February 17). Effects of magnesium pemoline and dextroamphetamine on human learning. Science, 155, 849-851. doi:10.1126/science.155.3764.849

Buschke, H. (1973). Selective reminding for analysis of memory and learning. Journal of Verbal Learning \& Verbal Behavior, 12, 543-550. doi:10.1016/S0022-5371(73)80034-9

Buschke, H., \& Fuld, P. A. (1974). Evaluation of storage, retention, and retrieval in disordered memory and learning. Neurology, 24, 1019-1025.

Callaway, E. (1983). Presidential address, 1982: The pharmacology of human information processing. Psychophysiology, 20, 359-370. doi: 10.1111/j.1469-8986.1983.tb00915.x

Camp-Bruno, J. A., \& Herting, R. L. (1994). Cognitive effects of milacemide and methylphenidate in healthy young adults. Psychopharmacology, 115, 46-52. doi:10.1007/BF02244750

Carroll, B. C., McLaughlin, T. J., \& Blake, D. R. (2006). Patterns and knowledge of nonmedical use of stimulants among college students. Archives of Pediatrics \& Adolescent Medicine, 160, 481-485. doi: 10.1001/archpedi.160.5.481

Clatworthy, P. L., Lewis, S. J., Brichard, L., Hong, Y. T., Izquierdo, D., Clark, L., . . Robbins, T. W. (2009). Dopamine release in dissociable striatal subregions predicts the different effects of oral methylphenidate on reversal learning and spatial working memory. Journal of Neuroscience, 29, 4690-4696. doi:10.1523/JNEUROSCI.3266-08.2009

Cooper, N. J., Keage, H., Hermens, D., Williams, L. M., Debrota, D., \& Clark, C. R. (2005). The dose-dependent effect of methylphenidate on performance, cognition, and psychophysiology. Journal of Integrative Neurosciences, 4, 123-144. doi:10.1142/S0219635205000744

Dean, W., \& Morgenthaler, J. (1990). Smart drugs \& nutrients: How to improve your memory and increase your intelligence using the latest discoveries in neuroscience. Petaluma, CA: Smart Publications.

DeSantis, A. D., Noar, S. M., \& Webb, E. M. (2009). Nonmedical ADHD stimulant use in fraternities. Journal of Studies on Alcohol and Drugs, 70, 952-954.

DeSantis, A. D., Webb, E. M., \& Noar, S. M. (2008). Illicit use of prescription ADHD medications on a college campus: A multimethodological approach. Journal of American College Health, 57, 315-324. doi:10.3200/JACH.57.3.315-324

D'Esposito, M., Postle, B. R., \& Rypma, B. (2000). Prefrontal cortical contributions to working memory: Evidence from event-related fMRI 
studies. Experimental Brain Research, 133, 3-11. doi:10.1007/ s002210000395

de Wit, H., Crean, J., \& Richards, J. B. (2000). Effects of d-amphetamine and ethanol on a measure of behavioral inhibition in humans. Behavioral Neuroscience, 114, 830-837. doi:10.1037/0735-7044.114.4.830

de Wit, H., Enggasser, J. L., \& Richards, J. B. (2002). Acute administration of d-amphetamine decreases impulsivity in healthy volunteers. Neuropsychopharmacology, 27, 813-825. doi:10.1016/S0893133X(02)00343-3

Diller, L. (1996). Use of growth hormone for non-growth hormone deficient children. JAMA, 276, 1877-1878. doi:10.1001/jama.276.23.1877

Docherty, J. R. (2008). Pharmacology of stimulants prohibited by the World Anti-Doping Agency (WADA). British Journal of Pharmacology, 154, 606-622. doi:10.1038/bjp.2008.124

Dockery, C. A., Hueckel-Weng, R., Birbaumer, N., \& Plewnia, C. (2009). Enhancement of planning ability by transcranial direct current stimulation. Journal of Neuroscience, 29, 7271-7277. doi:10.1523/ JNEUROSCI.0065-09.2009

Dodds, C. M., Muller, U., Clark, L., van Loon, A., Cools, R., \& Robbins, T. W. (2008). Methylphenidate has differential effects on blood oxygenation level-dependent signal related to cognitive subprocesses of reversal learning. Journal of Neuroscience, 28, 5976-5982. doi: 10.1523/JNEUROSCI.1153-08.2008

DuPont, R. L., Coleman, J. J., Bucher, R. H., \& Wilford, B. B. (2008). Characteristics and motives of college students who engage in nonmedical use of methylphenidate. American Journal on Addictions, 17, 167171. doi: $10.1080 / 10550490802019642$

Egan, M. F., Goldberg, T. E., Kolachana, B. S., Callicott, J. H., Mazzanti, C. M., Straub, R. E., ... Weinberger, D. R. (2001). Effect of COMT Val108/158 Met genotype on frontal lobe function and risk for schizophrenia. Proceedings of the National Academy of Sciences, USA, 98, 6917-6922. doi:10.1073/pnas.111134598

Elliott, R., Sahakian, B. J., Matthews, F., Bannerjea, A., Rimmer, J., \& Robbins, T. W. (1997). Effects of methylphenidate on spatial working memory and planning in healthy young adults. Psychopharmacology (Berlin), 131, 196-206.

Farah, M. J. (in press). Neuroscience and neuroethics in the 21st century. In J. Illes \& B. J. Sahakian (Eds.), The Oxford handbook of neuroethics. Oxford, England: Oxford University Press.

Farah, M. J., Illes, J., Cook-Deegan, R., Gardner, H., Kandel, E., King, P., ... Wolpe, P. R. (2004). Neurocognitive enhancement: What can we do and what should we do? Nature Reviews Neuroscience, 5, 421-425. doi: $10.1038 / \mathrm{nrn} 1390$

Fillmore, M. T., Kelly, T. H., \& Martin, C. A. (2005). Effects of $\mathrm{d}$-amphetamine in human models of information processing and inhibitory control. Drug and Alcohol Dependence, 77, 151-159. doi:10.1016/ j.drugalcdep.2004.07.013

Fitzpatrick, P., Klorman, R., Brumaghim, J. T., \& Keefover, R. W. (1988). Effects of methylphenidate on stimulus evaluation and response processes: Evidence from performance and event-related potentials. Psychophysiology, 25, 292-304. doi:10.1111/j.1469-8986.1988.tb01245.x

Fleming, K., Bigelow, L. B., Weinberger, D. R., \& Goldberg, T. E. (1995). Neuropsychological effects of amphetamine may correlate with personality characteristics. Psychopharmacology Bulletin, 31, 357-362.

Flöel, A., Rösser, N., Michka, O., Knecht, S., \& Breitenstein, C. (2008). Noninvasive brain stimulation improves language learning. Journal of Cognitive Neuroscience, 20, 1415-1422. doi:10.1162/jocn.2008.20098

Friedman, N. P., Miyake, A., Corley, R. P., Young, S. E., Defries, J. C., \& Hewitt, J. K. (2006). Not all executive functions are related to intelligence. Psychological Science, 17, 172-179. doi:10.1111/j.14679280.2006.01681.x

Froehlich, T. E., Lanphear, B. P., Epstein, J. N., Barbaresi, W. J., Katusic, S. K., \& Kahn, R. S. (2007). Prevalence, recognition, and treatment of attention-deficit/hyperactivity disorder in a national sample of US chil- dren. Archives of Pediatrics \& Adolescent Medicine, 161, 857-864. doi:10.1001/archpedi.161.9.857

Gazzaniga, M. S. (2005). The ethical brain. New York, NY: Dana Press. Giurgea, C. E. (1984). Psychopharmacology tomorrow: 1984 or the little prince? Psychological Medicine, 14, 491-496. doi:10.1017/ S0033291700015075

Grant, D. A., \& Berg, E. A. (1948). A behavioral analysis of degree of reinforcement and ease of shifting to new responses in a Weigl-type card-sorting problem. Journal of Experimental Psychology, 38, 404411.

Greely, H., Sahakian, B., Harris, J., Kessler, R. C., Gazzaniga, M., Campbell, P., \& Farah, M. J. (2008, December 11). Towards responsible use of cognitive-enhancing drugs by the healthy. Nature, 456, 702-705. doi:10.1038/456702a

Haier, R. J., Siegel, B. V., Tang, C., Abel, L., \& Buchsbaum, M. S. (1992). Intelligence and changes in regional cerebral glucose metabolic rate following learning. Intelligence, 16, 415-426. doi:10.1016/01602896(92)90018-M

Hall, K. M., Irwin, M. M., Bowman, K. A., Frankenberger, W., \& Jewett, D. C. (2005). Illicit use of prescribed stimulant medication among college students. Journal of American College Health, 53, 167-174. doi:10.3200/JACH.53.4.167-174

Halmøy, A., Fasmer, O. B., Gillberg, C., \& Haavik, J. (2009). Occupational outcome in adult ADHD: Impact of symptom profile, comorbid psychiatric problems, and treatment-A cross-sectional study of 414 clinically diagnosed adult ADHD patients. Journal of Attention Disorders, 13, 175-187. doi:10.1177/1087054708329777

Herman-Stahl, M. A., Krebs, C. P., Kroutil, L. A., \& Heller, D. C. (2007) Risk and protective factors for methamphetamine use and nonmedical use of prescription stimulants among young adults aged 18 to 25 . Addictive Behaviors, 32, 1003-1015. doi:10.1016/j.addbeh.2006.07.010

Hillman, C. H., Erickson, K. I., \& Kramer, A. F. (2008). Be smart, exercise your heart: Exercise effects on brain and cognition. Nature Reviews Neuroscience, 9, 58-65. doi:10.1038/nrn2298

Hurst, P. M., Radlow, R., \& Weidner, M. F. (1968). Effects of D-amphetamine on task-alternation and utility of delayed reward. American Journal of Psychology, 81, 391-397. doi:10.2307/1420636

Hurst, P. M., Weidner, M. F., \& Radlow, R. (1967). The effects of amphetamines upon judgments and decisions. Psychopharmacology, 11, 397-404. doi:10.1007/BF00405023

Johnston, L. D., O'Malley, P. M., Bachman, J. G., \& Schulenberg, J. E. (2009a). Monitoring the Future national survey results on drug use, 1975-2008: Volume I. Secondary school students (National Institutes of Health Publication No. 09-7402). Bethesda, MD: National Institute on Drug Abuse.

Johnston, L. D., O'Malley, P. M., Bachman, J. G., \& Schulenberg, J. E. (2009b). Monitoring the Future national survey results on drug use, 1975-2008: Volume II. College students and adults ages 19-50 (National Institutes of Health Publication No. 09-7403). Bethesda, MD: National Institute on Drug Abuse.

Judson, R., \& Langdon, S. W. (2009). Illicit use of prescription stimulants among college students: Prescription status, motives, theory of planned behavior, knowledge and self-diagnostic tendencies. Psychology, Health \& Medicine, 14, 97-104. doi:10.1080/13548500802126723

Julien, R. M. (2001). A primer of drug action. New York, NY: Holt.

Kaloyanides, K. B., McCabe, S. E., Cranford, J. A., \& Teter, C. J. (2007). Prevalence of illicit use and abuse of prescription stimulants, alcohol, and other drugs among college students: Relationship with age at initiation of prescription stimulants. Pharmacotherapy, 27, 666-674. doi: 10.1592/phco.27.5.666

Kennedy, R. S., Odenheimer, R. C., Baltzley, D. R., Dunlap, W. P., \& Wood, C. D. (1990). Differential effects of scopolamine and amphetamine on microcomputer-based performance tests. Aviation, Space, and Environmental Medicine, 61, 615-621. 
Kirschen, M. P., Davis-Ratner, M. S., Jerde, T. E., Schraedley-Desmond, P., \& Desmond, J. E. (2006). Enhancement of phonological memory following transcranial magnetic stimulation (TMS). Behavioural Neurology, 17, 187-194.

Klorman, R., Bauer, L. O., Coons, H. W., Lewis, J. L., Peloquin, J., Perlmutter, R. A., ... Strauss, J. (1984). Enhancing effects of methylphenidate on normal young adults' cognitive processes. Psychopharmacology Bulletin, 20, 3-9.

Kroutil, L. A., Van Brunt, D. L., Herman-Stahl, M. A., Heller, D. C., Bray, B. M., \& Penne, M. A. (2006). Nonmedical use of prescription stimulants in the United States. Drug and Alcohol Dependence, 84, 135-143. doi:10.1016/j.drugalcdep.2005.12.011

Kumari, V., Corr, P. J., Mulligan, O. F., Cotter, P. A., Checkley, S. A., \& Gray, J. A. (1997). Effects of acute administration of d-amphetamine and haloperidol on procedural learning in man. Psychopharmacology, 129, 271-276. doi:10.1007/s002130050190

Low, K. G., \& Gendaszek, A. E. (2002). Illicit use of psychostimulants among college students: A preliminary study. Psychology, Health \& Medicine, 7, 283-287. doi:10.1080/13548500220139386

Lutz, A., Slagter, H. A., Dunne, J. D., \& Davidson, R. J. (2008). Attention regulation and monitoring in meditation. Trends in Cognitive Sciences, 12, 163-169. doi:10.1016/j.tics.2008.01.005

Madrigal, A. (2008, April 9). 20 percent of scientists admit using brainenhancing drugs- do you? Wired. Retrieved from http://www.wired .com/wiredscience/2008/04/20-of-scientist/

Maher, B. (2008, April 9). Poll results: Look who's doping. Nature, 452, 674-675. doi:10.1038/452674a

Makris, A. P., Rush, C. R., Frederich, R. C., Taylor, A. C., \& Kelly, T. H. (2007). Behavioral and subjective effects of d-amphetamine and modafinil in healthy adults. Experimental and Clinical Psychopharmacology, 15, 123-133. doi:10.1037/1064-1297.15.2.123

Mattay, V. S., Berman, K. F., Ostrem, J. L., Esposito, G., Van Horn, J. D., \& Bigelow, L. B. (1996). Dextroamphetamine enhances "neural network-specific" physiological signals: A positron-emission tomography rCBF study. Journal of Neuroscience, 16, 4816-4822.

Mattay, V. S., Callicott, J. H., Bertolino, A., Heaton, I., Frank, J. A., Coppola, R., ... Weinberger, D. R. (2000). Effects of dextroamphetamine on cognitive performance and cortical activation. Neurolmage, 12, 268-275. doi:10.1006/nimg.2000.0610

Mattay, V. S., Goldberg, T. E., Fera, F., Hariri, A. R., Tessitore, A., Egan, M. F., ... Weinberger, D. R. (2003). Catechol O-methyltransferase val158-met genotype and individual variation in the brain response to amphetamine. Proceedings of the National Academy of Sciences, USA, 100, 6186-6191. doi:10.1073/pnas.0931309100

McCabe, S. E., \& Boyd, C. J. (2005). Sources of prescription drugs for illicit use. Addictive Behaviors, 30, 1342-1350. doi:10.1016/j.addbeh.2005.01.012

McCabe, S. E., Knight, J. R., Teter, C. J., \& Wechsler, H. (2005). Non-medical use of prescription stimulants among US college students: Prevalence and correlates from a national survey. Addiction, 100, 96106. doi:10.1111/j.1360-0443.2005.00944.x

McCabe, S. E., Teter, C. J., \& Boyd, C. J. (2004). The use, misuse and diversion of prescription stimulants among middle and high school students. Substance Use \& Misuse, 39, 1095-1116. doi:10.1081/JA120038031

McCabe, S. E., Teter, C. J., \& Boyd, C. J. (2006). Medical use, illicit use, and diversion of prescription stimulant medication. Journal of Psychoactive Drugs, 38, 43-56. doi:10.3200/JACH.54.5.269-278

Mehlman, M. J. (2004). Cognition-enhancing drugs. Milbank Quarterly, 82, 483-506. doi:10.1111/j.0887-378X.2004.00319.x

Mehta, M. A., Owen, A. M., Sahakian, B. J., Mavaddat, N., Pickard, J. D., \& Robbins, T. W. (2000). Methylphenidate enhances working memory by modulating discrete frontal and parietal lobe regions in the human brain. Journal of Neuroscience, 20, RC65.

Mintzer, M. Z., \& Griffiths, R. R. (2007). A triazolam/amphetamine dose-effect interaction study: Dissociation of effects on memory versus arousal. Psychopharmacology, 192, 425-440. doi:10.1007/s00213-0070726-y

Minzenberg, M. J., \& Carter, C. S. (2008). Modafinil: A review of neurochemical actions and effects on cognition. Neuropsychopharmacology, 33, 1477-1502. doi:10.1038/sj.npp.1301534

MTA Cooperative Group. (1999). 14-month randomized clinical trial of treatment strategies for attention deficit hyperactivity disorder. Archives of General Psychiatry, 56, 1073-1086. doi:10.1001/archpsyc.56.12.1073

Novak, S. P., Kroutil, L. A., Williams, R. L., \& Van Brunt, D. L. (2007). The nonmedical use of prescription ADHD medications: Results from a national Internet panel. Substance Abuse Treatment, Prevention, and Policy, 2:32. doi:10.1186/1747-597X-2-32

Oken, B. S., Kishiyama, S. S., \& Salinsky, M. C. (1995). Pharmacologically induced changes in arousal: Effects on behavioral and electrophysiologic measures of alertness and attention. Electroencephalography \& Clinical Neurophysiology, 95, 359-371. doi:10.1016/00134694(95)00124-H

Owen, A. M. (2000). The role of the lateral frontal cortex in mnemonic processing: The contribution of functional neuroimaging. Experimental Brain Research, 133, 33-43. doi:10.1007/s002210000398

Pliszka, S. R. (2005). The neuropsychopharmacology of attention-deficit/ hyperactivity disorder. Biological Psychiatry, 57, 1385-1390. doi: 10.1016/j.biopsych.2004.08.026

Poulin, C. (2001). Medical and nonmedical stimulant use among adolescents: From sanctioned to unsanctioned use. CMAJ: Canadian Medical Association Journal/Journal de l'Association Medicale Canadienne, 165, 1039-1044.

Poulin, C. (2007). From attention-deficit/hyperactivity disorder to medical stimulant use to the diversion of prescribed stimulants to non-medical stimulant use: Connecting the dots. Addiction, 102, 740-751. doi: 10.1111/j.1360-0443.2007.01758.x

Rabiner, D. L., Anastopoulos, A. D., Costello, E. J., Hoyle, R. H., McCabe, S. E., \& Swartzwelder, H. S. (2009). Motives and perceived consequences of nonmedical ADHD medication use by college students: Are students treating themselves for attention problems? Journal of Attention Disorders, 13, 259-270. doi:10.1177/1087054708320399

Rapoport, J. L., Buchsbaum, M. S., \& Weingartner, H. (1980). Dextroamphetamine: Cognitive and behavioral effects in normal and hyperactive boys and normal adult males. Psychopharmacology Bulletin, 16, 21-23.

Rasmussen, N. (2008). On speed: The many lives of amphetamine. New York, NY: New York University Press.

Raven, J. C. (1990). Manual for Raven's Progressive Matrices and Vocabulary Scales (2nd ed.). Oxford, England: Oxford Psychologists Press.

Robbins, T. W., \& Arnsten, A. F. (2009). The neuropsychopharmacology of fronto-executive function: Monoaminergic modulation. Annual Review of Neuroscience, 32, 267-287. doi:10.1146/annurev.neuro .051508 .135535

Robbins, T. W., \& Everett, B. J. (1996). Neurobehavioral mechanisms of reward and motivation. Current Opinion in Neurobiology, 6, 228-236. doi:10.1016/S0959-4388(96)80077-8

Rogers, R. D., Blackshaw, A. J., Middleton, H. C., Matthews, K., Hawtin, K., Crowley, C., ... Robbins, T. W. (1999). Tryptophan depletion impairs stimulus-reward learning while methylphenidate disrupts attentional control in healthy young adults: Implications for the monoaminergic basis of impulsive behaviour. Psychopharmacology, 146, 482 491. doi:10.1007/PL00005494

Sahakian, B., \& Morein-Zamir, S. (2007, December 20). Professor's little helper. Nature, 450, 1157-1159. doi:10.1038/4501157a

Sahakian, B. J., \& Owen, A. M. (1992). Computerized assessment in neuropsychiatry using CANTAB: Discussion paper. Journal of the Royal Society of Medicine, 85, 399-402.

Sankaranarayanan, J., Puumala, S. E., \& Kratochvil, C. J. (2006). Diagnosis and treatment of adult attention-deficit/hyperactivity disorder at 
US ambulatory care visits from 1996 to 2003. Current Medical Research and Opinion, 22, 1475-1491. doi:10.1185/030079906X112615

Schlösser, R. G. M., Nenadic, I., Wagner, G., Zysset, S., Koch, K., \& Sauer, H. (2009). Dopaminergic modulation of brain systems subserving decision making under uncertainty: A study with fMRI and methylphenidate challenge. Synapse, 63, 429-442. doi:10.1002/syn.20621

Schmedtje, J. F., Jr., Oman, C. M., Letz, R., \& Baker, E. L. (1988). Effects of scopolamine and dextroamphetamine on human performance. Aviation, Space, and Environmental Medicine, 59, 407-410.

Schroeder, S. R., Mann-Koepke, K., Gualtieri, C. T., Eckerman, D. A., \& Breese, G. R. (1987). Methylphenidate affects strategic choice behavior in normal adult humans. Pharmacology, Biochemistry and Behavior, 28, 213-217. doi:10.1016/0091-3057(87)90217-6

Servan-Schreiber, D., Carter, C. S., Bruno, R. M., \& Cohen, J. D. (1998). Dopamine and the mechanisms of cognition: Part II. D-amphetamine effects in human subjects performing a selective attention task. Biological Psychiatry, 43, 723-729. doi:10.1016/S0006-3223(97)00449-6

Shillington, A. M., Reed, M. B., Lange, J. E., Clapp, J. D., \& Henry, S. (2006). College undergraduate Ritalin abusers in southwestern California: Protective and risk factors. Journal of Drug Issues, 36, 999-1014.

Silber, B. Y., Croft, R. J., Papafotiou, K., \& Stough, C. (2006). The acute effects of d-amphetamine and methamphetamine on attention and psychomotor performance. Psychopharmacology, 187, 154-169. doi: 10.1007/s00213-006-0410-7

Singh, I., \& Kelleher, K. J. (2010). Neuroenhancement in young people: Proposal for research, policy, and clinical management. AJOB Neuroscience, 1, 3-16.

Snodgrass, J., \& LeBaron, P. (2007). 2008 National Survey on Drug Use and Health: CAI specifications for programming English version. Retrieved from http://www.oas.samhsa.gov/nsduh/2k8MRB/2k8Q.pdf

Soetens, E., Casaer, S., D'Hooge, R., \& Hueting, J. E. (1995). Effect of amphetamine on long-term retention of verbal material. Psychopharmacology, 119, 155-162. doi:10.1007/BF02246156

Soetens, E., D'Hooge, R., \& Hueting, J. E. (1993). Amphetamine enhances human-memory consolidation. Neuroscience Letters, 161, 9-12. doi: 10.1016/0304-3940(93)90127-7

Sternberg, S. (1966, August 5). High-speed scanning in human memory. Science, 153, 652-654. doi:10.1126/science.153.3736.652

Strauss, J., Lewis, J. L., Klorman, R., Peloquin, L. J., Perlmutter, R. A., \& Salzman, L. F. (1984). Effects of methylphenidate on young adults' performance and event-related potentials in a vigilance and a pairedassociates learning test. Psychophysiology, 21, 609-621. doi:10.1111/ j.1469-8986.1984.tb00247.x

Substance Abuse and Mental Health Services Administration. (2009). Results from the 2008 National Survey on Drug Use and Health: National findings (U.S. Department of Health and Human Services Publication No. SMA 09-4434). Rockville, MD: Author. Retrieved from www.oas.samhsa.gov/nsduh/2k8nsduh/2k8Results.pdf

Swanson, J., Arnold, L. E., Kraemer, H., Hechtman, L., Molina, B., Hinshaw, S., ... Wigal, T. (2008). Evidence, interpretation and qualification from multiple reports of long-term outcomes in the Multimodal Treatment Study of Children With ADHD (MTA): Part II. Supporting details. Journal of Attention Disorders, 12, 15-43. doi:10.1177/ 1087054708319525

Teter, C. J., McCabe, S. E., Boyd, C. J., \& Guthrie, S. K. (2003). Illicit methylphenidate use in an undergraduate student sample: Prevalence and risk factors. Pharmacotherapy, 23, 609-617. doi:10.1592/ phco.23.5.609.34187

Teter, C. J., McCabe, S. E., Cranford, J. A., Boyd, C. J., \& Guthrie, S. K. (2005). Prevalence and motives for illicit use of prescription stimulants in an undergraduate student sample. Journal of American College Health, 53, 253-262. doi:10.3200/JACH.53.6.253-262

Teter, C. J., McCabe, S. E., LaGrange, K., Cranford, J. A., \& Boyd, C. J.
(2006). Illicit use of specific prescription stimulants among college students: Prevalence, motives, and routes of administration. Pharmacotherapy, 26, 1501-1510. doi:10.1592/phco.26.10.1501

Thalheimer, W., \& Cook, S. (2002, August). How to calculate effect sizes from published research articles: A simplified methodology. Retrieved from http://work-learning.com/effect_sizes.htm

Tipper, C. M., Cairo, T. A., Woodward, T. S., Phillips, A. G., Liddle, P. F., \& Ngan, E. T. (2005). Processing efficiency of a verbal working memory system is modulated by amphetamine: An fMRI investigation. Psychopharmacology, 180, 634-643. doi:10.1007/s00213-005-0025-4

Unrug, A., Coenen, A., \& van Luijtelaar, G. (1997). Effects of the tranquilizer diazepam and the stimulant methylphenidate on alertness and memory. Neuropsychobiology, 36, 42-48. doi:10.1159/000119359

Van Dongen, H. P., Maislin, G., Mullington, J. M., \& Dinges, D. F. (2003). The cumulative cost of additional wakefulness: Dose-response effects on neurobehavioral functions and sleep physiology from chronic sleep restriction and total sleep deprivation. Sleep: Journal of Sleep and Sleep Disorders Research, 26, 117-126.

Vastag, B. (2004). Poised to challenge need for sleep, "wakefulness enhancer" rouses concerns. JAMA, 291, 167-170. doi:10.1001/ jama.291.2.167

Volkow, N. D., Wang, G. J., Fowler, J. S., Telang, F., Maynard, L., Logan, J., ... Swanson, J. M. (2004). Evidence that methylphenidate enhances the saliency of a mathematical task by increasing dopamine in the human brain. American Journal of Psychiatry, 161, 1173-1180. doi:10.1176/ appi.ajp.161.7.1173

Volkow, N. D., Wang, G. J., Newcorn, J., Fowler, J. S., Telang, F., Solanto, M. V., ... Pradhan, K. (2007). Brain dopamine transporter levels in treatment and drug naive adults with ADHD. NeuroImage, 34, 11821190. doi:10.1016/j.neuroimage.2006.10.014

Ward, A. S., Kelly, T. H., Foltin, R. W., \& Fischman, M. W. (1997). Effects of d-amphetamine on task performance and social behavior of humans in a residential laboratory. Experimental and Clinical Psychopharmacology, 5, 130-136. doi:10.1037/1064-1297.5.2.130

Weitzner, M. (1965). Manifest anxiety, amphetamine, and performance. Journal of Psychology: Interdisciplinary and Applied, 60, 71-79.

Weyandt, L. L., Janusis, G., Wilson, K. G., Verdi, G., Paquin, G., Lopes, J., ... Dussault, C. (2009). Nonmedical prescription stimulant use among a sample of college students: Relationship with psychological variables. Journal of Attention Disorders, 3, 284-296. doi:10.1177/ 1087054709342212

White, B. P., Becker-Blease, K. A., \& Grace-Bishop, K. (2006). Stimulant medication use, misuse, and abuse in an undergraduate and graduate student sample. Journal of American College Health, 54, 261-268. doi:10.3200/JACH.54.5.261-268

Wilens, T. E. (2006). Mechanism of action of agents used in attentiondeficit/hyperactivity disorder. Journal of Clinical Psychiatry, 67(Suppl. 8), 32-38.

Willett, R. A. (1962). The effect of a stimulant and a depressant drug on the serial rote learning of nonsense syllables. Psychopharmacologia, 3, 23-34. doi:10.1007/BF00413103

Wilson, D. E., Chernov, H. I., Bernard, P. S., Partyka, D. A., Barbaz, B. S., \& DeStevens, G. (1971). Neuropharmacological properties of Su17595A a chlorpromazine-like central nervous system depressant. Archives Internationales de Pharmacodynamie et de Therapie, 191, 15-23.

Zeeuws, I., \& Soetens, E. (2007). Verbal memory performance improved via an acute administration of D-amphetamine. Human Psychopharmacology: Clinical \& Experimental, 22, 279-287. doi:10.1002/hup.848

Received July 20, 2008

Revision received January 9, 2011 Accepted January 11, 2011 


\section{AUTHOR QUERIES}

\section{AUTHOR PLEASE ANSWER ALL QUERIES}

AQ1: Author: Table 1 has a footnote citing McCabe, Boyd, \& Young (2007), which is not on your reference list. Please provide a complete citation.

AQ2: Author: In Table 2 (and in Table 4), you mention the BX version of the continuous performance test. What does BX stand for? Also in Table 2, you mention the following study that does not appear on your reference list. Please provide complete citations for the following: Wilson et al. (2004).

AQ3: Author: In Table 3, you mention Fleming (1993) but this study does not appear on your reference list. Please provide a complete citation.

AQ4: Author: In Table 4, you mention the following studies that do not appear on your reference list. Please provide complete citations for the following: Barch (2005), Elliott (1997), Mehta (2000), and Wilson (2004).

AQ5: Author: Please provide a reference citation for the Wechsler IQ test.

AQ6: Author: In Table 5, you mention the following studies that do not appear on your reference list. Please provide complete citations for Barch (2005), and Elliott (1997).

AQ7: Author: In Table 6, you mention the following study that does not appear on your reference list. Please provide a complete citation for Elliott (1997).

AQ8: Author: APA has a policy against thanking anonymous reviewers in the author note, so I have deleted that language from your author note. If you wish to express indebtedness to an anonymous reviewer for a particular point or suggestion, you may do so via a footnote at the appropriate spot in the text. 